\title{
Ensemble projections of future streamflow droughts in Europe
}

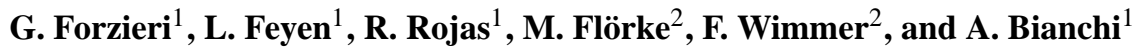 \\ ${ }^{1}$ Climate Risk Management Unit, Institute for Environment and Sustainability, Joint Research Centre, \\ European Commission, Ispra, Italy \\ ${ }^{2}$ Center for Environmental Systems Research (CESR), University of Kassel, Kassel, Germany \\ Correspondence to: G. Forzieri (giovanni.forzieri@jrc.ec.europa.eu)
}

Received: 8 August 2013 - Published in Hydrol. Earth Syst. Sci. Discuss.: 16 August 2013

Revised: 22 November 2013 - Accepted: 27 November 2013 - Published: 9 January 2014

\begin{abstract}
There is growing concern in Europe about the possible rise in the severity and frequency of extreme drought events as a manifestation of climate change. In order to plan suitable adaptation strategies it is important for decision makers to know how drought conditions will develop at regional scales. This paper therefore addresses the issue of future developments in streamflow drought characteristics across Europe. Through offline coupling of a hydrological model with an ensemble of bias-corrected climate simulations (IPCC SRES A1B) and a water use scenario (Economy First), long-term (1961-2100) ensemble streamflow simulations are generated that account for changes in climate, and the uncertainty therein, and in water consumption. Using extreme value analysis we derive minimum flow and deficit indices and evaluate how the magnitude and severity of lowflow conditions may evolve throughout the 21 st century. This analysis shows that streamflow droughts will become more severe and persistent in many parts of Europe due to climate change, except for northern and northeastern parts of Europe. In particular, southern regions will face strong reductions in low flows. Future water use will aggravate the situation by $10-30 \%$ in southern Europe, whereas in some sub-regions in western, central and eastern Europe a climate-driven signal of reduced droughts may be reversed due to intensive water use. The multi-model ensemble projections of more frequent and severe streamflow droughts in the south and decreasing drought hazard in the north are highly significant, while the projected changes are more dissonant in a transition zone in between.
\end{abstract}

\section{Introduction}

Drought is a natural feature of the water cycle that can occur in all climatic zones. It originates from a temporary aberration of the normal precipitation regime over a large area, but other climatic factors, such as high temperatures and winds or low relative humidity, can significantly aggravate the severity of the event. Anthropogenic drivers, such as intensive water use and poor water management, can further exacerbate low-flow conditions in watersheds, with a consequent increase in vulnerability to drought (e.g., Vörösmarty et al., 2000; Tallaksen and van Lanen 2004; Döll et al., 2009; Wada et al., 2013a). Water scarcity reflects the imbalance that arises from an overexploitation of water resources, caused by consumption being significantly higher than the natural renewable availability (Schmidt and Benítez-Sanz, 2013; Van Loon and Van Lanen, 2013). Albeit water scarcity may relate to any hydrological condition, it is more likely to occur under drought conditions due to reduced water availability.

Climate warming is expected to considerably alter the water balance throughout Europe, with higher temperatures resulting in higher potential evapotranspiration as well as in changes in the spatial and temporal distribution of precipitation, including more frequent and persistent dry spells (e.g., Rowell, 2005; Beniston et al., 2007, Christensen and Christensen, 2007; van der Linden and Mitchell, 2009; Nikulin et al., 2011). Hence, with a warmer climate, droughts could become more frequent, severe, and longer-lasting in Europe.

Compared to other natural hazards, such as floods, tornadoes and earthquakes, there is a general lower public awareness of droughts because they usually develop slower and more imperceptibly. Nevertheless, the potential increase in drought hazard with human-induced climate warming has 
recently become a great concern for the EU (EC, 2007, 2012) given the stresses being placed on water resources and the considerable economical, societal and environmental impacts. In the last two decades, the average annual economic consequences of droughts in Europe drastically increased,

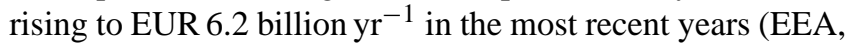
2010). The severe drought that hit southern and central Europe in the summer of 2003 - with an economic damage of more than EUR 8.7 billion (EEA, 2010) - showed what the impacts might be if climate change leads to an increase in the frequency and intensity of droughts across Europe (Schär et al., 2004).

There is medium confidence that since the 1950s southern Europe has experienced a trend toward more intense and longer droughts (IPCC, 2012). Stahl et al. (2010) show a trend towards decreasing low flows in most regions of Europe where the lowest mean monthly flow occurs in summer. Some regional studies have confirmed the trend towards reduced low-flow conditions in southern and eastern Norway (Wilson et al., 2010), the Pyrenees in France (Renard et al., 2008), and the Czech Republic (Fiala et al., 2010). Further, recent global (Dai, 2013; Sheffield et al., 2012) and regional (Hoerling et al., 2012; Stahl et al., 2012) studies found a consistent tendency of increasing drought over the 20th century in Mediterranean regions. However, Orlowsky and Seneviratne (2013) pointed out that the detection of trends may be largely dependent on the investigated drought indices, time periods analyzed and ways to assess the statistical significance of the trends. These factors can explain some contradictory results, found for example over central and northern Europe, which highlight the intrinsic ambiguity in quantifying trends in droughts (Orlowsky and Seneviratne, 2013). Detecting a climate change signal in the occurrence and severity of droughts can be further complicated, as it may be hidden beneath the strong inter-annual to decadal natural climate variability. Moreover, catchments in Europe are often heavily disturbed by human influences, which potentially mask the effects of global warming on watershed dynamics. For example, in many river basins in Europe the installment of reservoirs in the course of the 20th century has led to less severe streamflow drought conditions (Svensson et al., 2005). However, increasing low flows have also been observed in half of the undisturbed catchments in Finland (Korhonen and Kuusisto, 2010).

Different types of drought can be distinguished, namely meteorological (precipitation deficit), soil moisture (insufficient soil moisture for plant growth), and hydrological drought (deficiency in the bulk water availability). In literature the focus has been largely on the first two aspects. As a result, assessments of future droughts have mainly focused on changes in temperature and precipitation (e.g., Beniston et al., 2007; Blenkinsop and Fowler, 2007; Calanca, 2007; Vidal and Wade, 2009; Sienz et al., 2012; Vidal et al., 2012), or have evaluated changes in soil moisture derived from land surface schemes of climate models (e.g., Burke and Brown,
2008; Sheffield and Wood, 2008; Dai, 2011; Heinrich and Gobiet, 2012).

Sectors such as energy production, river navigation, irrigated agriculture, and public water supply, are directly affected by low surface water levels and limited groundwater storage. To complement studies focusing on meteorological and soil moisture drought, this study focuses on changes in hydrological droughts, through the evaluation of anomalies in the low-flow spectrum across Europe in view of climate change and water demand projections.

In recent literature, a large number of studies have evaluated the potential impacts of global warming on different components of the hydrological cycle. Relatively few works, however, have focused on changes in low flows (Diaz-Nieto and Wilby, 2005; de Wit et al., 2007; Hurkmans et al., 2010; Majone et al., 2012). Large-scale analyses include the global assessment by Hirabayashi et al. (2008), the works of Lehner et al. (2006) and Feyen and Dankers (2009) for Europe, and of Weiss et al. (2007) for the Mediterranean region. Whereas Hirabayashi et al. (2008) analyzed directly simulated discharges from a GCM (global circulation model), Lehner et al. (2006) and Weiss et al. (2007) applied the monthlyaveraged climate change signal of GCMs to observationbased data sets (i.e., a delta change approach), which were then used to drive the WaterGAP global hydrology and water use model (Alcamo et al., 2003; Döll et al., 2003). The coarse temporal and spatial resolution of the climate signal used in these studies, however, does not reflect well the potential changes in sub-monthly extreme events at regional and local scales.

The pan-European assessment of Feyen and Dankers (2009), on the other hand, employed highresolution regional climate data from a single regional climate model (RCM) to force a European-wide hydrological model to assess daily climate-related alterations in the low-flow spectrum. They derived low-flow characteristics from the simulated streamflow series using extreme value analysis and assessed changes in the magnitude and intensity of streamflow droughts. Results indicated that under the IPCC SRES A2 scenario (see Nakicenovic and Swart, 2000) streamflow droughts will become more severe and persistent in most parts of Europe by the end of this century, except in the most northern and northeastern regions.

These conclusions, however, depend not only on the choice of greenhouse gas emission scenario, but also on the climate model used, as climate model configuration remains the main source of uncertainty in climate projections, especially for European precipitation (Déqué et al., 2007, 2012). Over midlatitudes in Europe, models even show a disagreement in the direction of change in annual precipitation (see Fig. 11.5 in Christensen et al., 2007). Whereas the magnitude of change in (extreme) precipitation that is simulated by RCMs is, for a large part, determined by the driving global model, the regional model formulation influences the spatial pattern (Fowler et al., 2007). This is because the large-scale 
circulation patterns within RCMs largely depend on the lateral boundary conditions from their driving GCM, influencing not only the mean precipitation changes but also the extremes. Considering uncertainties in low precipitation extremes, Blenkinsop and Fowler (2007) demonstrated considerable dependency on the driving GCM for future projections, particularly for drought frequency. Following this, an ensemble-based framework considering multiple driving climate projections will provide a more robust estimation of the future changes in streamflow drought hazard.

Recent developments of water use scenarios, which foreshadow possible future water consumptions in Europe, further opened new opportunities for an integrated assessment of water resources (Schaldach et al., 2012). Even if water use modules have been already efficiently embedded into largescale hydrological models to investigate water availability (Aus der Beek et al., 2010; Flörke et al., 2012, 2013), the potential intensification of future streamflow droughts due to water consumption needs to be properly assessed (e.g., Wada et al., 2013a).

This work provides a high-resolution appraisal of future developments in streamflow drought in Europe accounting for the major drivers of possible changes in the temporal and spatial availability of water. The present paper builds on the work of Feyen and Dankers (2009) but shows several innovative aspects, which overcome some limitations identified in previous works. First, we present an in-depth analysis of the robustness and significance of the projected changes in streamflow drought, simulated by the LISFLOOD hydrological model (van der Knijff et al., 2010), in view of uncertainty in future climate developments. To this end we assess changes in low-flow conditions in Europe throughout the 21 st century using a large ensemble (12 members) of biascorrected climate projections (IPCC SRES A1B) from the EU FP6 ENSEMBLES project (van der Linden and Mitchell, 2009). In addition, we assess the impact of intensive water use on streamflow drought conditions by incorporating projections of water consumption under an A1B-consistent scenario (Economy First - EcF) from the EU FP6 SCENES project (Flörke et al., 2011). Finally, we also validate the estimation of streamflow indices against a very large validation set (446 stations across Europe) and evaluate the extreme value fitting uncertainty at these stations. In the following sections, the different steps of the methodology are detailed, followed by a discussion of the results and conclusions.

\section{Methodology}

\subsection{Climate and water use scenarios}

Estimates of future changes in hydrological droughts are intrinsically dependent on multiple sources of variability that propagate through the modeling chain. The choice of a greenhouse gas emission and water use consumption scenario plays a determinant role to pre-estimate future human influences affecting the global climate system and water demand. Scenarios are alternative pictures of how the future might unfold and are based on a set of environmental and socioeconomic assumptions. They serve as a basis to study the potential future pathways of climate change and water resource developments that are either inherently unpredictable or that have high uncertainties (Nakicenovic and Swart, 2000; Alcamo, 2008; Moss et al., 2010; Schaldach et al., 2012).

The analysis presented herein is based on a set of highresolution climate simulations from the EU FP6 ENSEMBLES project (van der Linden and Mitchell, 2009). In total, 12 climate experiments derived from a combination of 4 GCMs and 7 RCMs, covering the period 1961-2100, were used (see Table 1). These nested GCM-RCM simulations have a horizontal resolution of ca. $25 \mathrm{~km}$, a daily temporal resolution, and were forced by the IPCC SRES A1B scenario (Nakicenovic and Swart, 2000). We focus on the ENSEMBLES SRES-A1B data set as to date it is the only large ensemble of high-resolution climate simulations for Europe that allows for a finer assessment of the climate model uncertainty (van der Linden and Mitchell, 2009). The A1B scenario projects a fast economic growth, global population peaking in mid-century, rapid introduction of new and more efficient technologies, and a balance across all energy sources (Nakicenovic and Swart, 2000). The climate experiments were corrected for bias in the precipitation and minimum, average, and maximum temperature fields using the quantile mapping (QM) method (Piani et al., 2010a, b; Dosio et al., 2012). Several techniques to correct potential bias in precipitation and temperature have been recently developed in literature based on different transfer functions and theoretical assumptions (Teutschbein and Seibert, 2010; Themeßl et al., 2011). We implemented the QM method because it showed better performance compared to other methods to correct for bias in high-resolution regional climate models (Themeßl et al., 2011). On the basis of the stationarity assumption (Christensen et al., 2008), current performance for the bias correction methods may be deemed transferable to future climate. Dosio and Paruolo (2011) showed that the QM bias correction procedure drastically improved the agreement between simulated and observed climatology from the E-OBS data set (Haylock et al., 2008). Moreover, it has been shown to yield improvements in both the upper and lower tail of the probability distribution functions (PDFs) of temperature and precipitation, with significantly positive effects on the accuracy of simulated extreme climatic and hydrological events (Dosio and Paruolo, 2011; Rojas et al., 2011).

To evaluate the potential effects of water consumption on streamflow drought indices a spatially distributed quantitative water use scenario from WaterGAP3 (aus der Beek et al., 2010; Flörke et al., 2012; Schaldach et al., 2012; Flörke et al., 2013) was used. WaterGAP3 consists of different sub-models 
Table 1. Climate simulations used to drive LISFLOOD in the period 1961-2100.

\begin{tabular}{|c|c|c|c|c|}
\hline Model & Driving GCM & $\mathrm{RCM}$ & Institute & Acronyms \\
\hline 1 & $\operatorname{HadCM} 3 Q 16^{\mathrm{a}}$ & RCA3.0 & The Community Climate Change Consortium for Ireland & C4I-RCA-HadCM3 \\
\hline 2 & ARPEGE & ALADIN-RM5.1 & Centre National de Recherches Météorologiques, Meteo France & CNRM-ALADIN-ARPEGE \\
\hline 3 & ARPEGE & HIRHAM5 & Danish Meteorological Institute & DMI-HIRHAM5-ARPEGE \\
\hline 4 & $\mathrm{BCM}$ & HIRHAM5 & Danish Meteorological Institute & DMI-HIRHAM5-BCM \\
\hline 5 & ECHAM5-r $3^{b}$ & HIRHAM5 & Danish Meteorological Institute & DMI-HIRHAM5-ECHAM5 \\
\hline 6 & $\operatorname{HadCM} 3 \mathrm{Q} 0^{\mathrm{a}}$ & CLM & Swiss Federal Institute of Technology & ETHZ-CLM-HadCM3 \\
\hline 7 & ECHAM5-r $3^{b}$ & RACMO2 & The Royal Netherlands Meteorological Institute & KNMI-RACMO2-ECHAM5 \\
\hline 8 & HadCM3Q0 $0^{\mathrm{a}}$ & HadRM3Q0 & Hadley Centre for Climate Prediction and Research, UK & METO-HadRM3-HadCM3 \\
\hline 9 & ECHAM5-r $3^{\mathrm{b}}$ & REMO & Max-Planck-Institute for Meteorology, Germany & MPI-REMO-ECHAM5 \\
\hline 10 & $\mathrm{BCM}$ & RCA3.0 & Swedish Meteorological and Hydrological Institute & SMHI-RCA-BCM \\
\hline 11 & ECHAM5-r $3^{b}$ & RCA3.0 & Swedish Meteorological and Hydrological Institute & SMHI-RCA-ECHAM5 \\
\hline 12 & $\mathrm{HadCM}_{3} \mathrm{Q}^{\mathrm{a}}$ & RCA3.0 & Swedish Meteorological and Hydrological Institute & SMHI-RCA-HadCM3 \\
\hline
\end{tabular}

a Represent three versions of the HadCM3 model with perturbed parameterization impacting the simulated climate response sensitivities: Q0 (reference), Q3 (low-sensitivity) and Q16 (high-sensitivity) (Collins et al., 2006). ${ }^{\text {b }}$ Represent one run of the ECHAM5 model using three different sets of initial conditions defined as "-r1", “-r2", and "-r3" (Kendon et al., 2010).

to determine water withdrawal and consumption in different sectors (domestic, tourism, energy, manufacturing, irrigation and livestock). The water use scenario was taken from the SCENES project (Kämäri et al., 2008, Kok et al., 2011), which aimed at developing and analyzing a set of comprehensive water-related scenarios for Europe through a participatory process. Four comprehensive scenarios were developed: Economy First (EcF), Fortress Europe (FoE), Policy Rules (PoR), and Sustainability Eventually (SuE). The scenarios include consistent projections of the main drivers such as total population, GDP (gross domestic product), thermal electricity production, agricultural production as well as information on technological changes. The EcF scenario was selected as it is the most coherent with the IPCC SRES A1B. It is characterized by a globalized and liberalized economy pushing the use of all available energy sources accompanied by a marked agricultural intensification. The adoption of new technologies and a water-saving consciousness is low resulting in an increasing water demand of all water-related sectors. Only water ecosystems providing ecological goods and services for economies are preserved and improved (Kok et al., 2011).

Within SCENES, water uses for the different sectors are modeled on an annual basis, except for the irrigation water use which has a monthly temporal resolution. Note that the SCENES scenarios run until 2050. For the remaining period it was assumed that water consumption remains unchanged from 2050 onwards.

\subsection{Hydrological modeling}

River discharge simulations for different climate experiments (see Table 1) were obtained using the LISFLOOD model (van der Knijff et al., 2010). Being a fully distributed and physically based hydrological model developed for largescale impact assessment studies, LISFLOOD simulates the spatial and temporal patterns of catchment responses as a function of spatial information on meteorology, topography, soils, and land cover. It has been specifically set up for European catchments by optimally exploiting several databases that contain pan-European information on soils (King et al., 1994; Wösten et al., 1999), land cover (European Environment Agency, 2002), topography (Hiederer and de Roo, 2003) and meteorology (Rijks et al., 1998). LISFLOOD is a GIS-based hydrological model where processes such as infiltration, water consumption by plants, snowmelt, freezing of soils, surface runoff and groundwater storage are explicitly accounted for at the grid level. Spatial properties for soils, vegetation types, land uses, and river channels constitute the basic input information to set up a LISFLOOD run, whereas data on precipitation, air temperature, potential evapotranspiration, and evaporation from water bodies and bare soil surfaces are the main meteorological drivers.

Potential evapotranspiration and evaporation rates are calculated from vapor pressure, wind speed, radiation (solar + thermal), albedo, and average, minimum, maximum and dew point temperature through the offline LISVAP preprocessor based on the Penman-Monteith equation (van der Knijff, 2008). We point out that variables such as dewpoint temperature, solar and thermal radiation that are employed together with the bias-corrected temperature fields to calculate the evapotranspiration components driving LISFLOOD are not corrected for potential bias. This could violate the energy balance and potentially introduce bias in the simulated hydrological patterns (e.g., Rojas et al., 2011; Hagemann et al., 2013). However, experiments performed using the same bias correction method with a different impact model showed that the relative values of projected hydrological change are very similar if other climate variables are also bias corrected (Haddeland et al., 2012). Thus, we can reasonably presume that the impact of these inconsistencies is generally rather small.

We also recognize the potential importance of reservoirs and flow regulation for hydrological low-flow analysis, 
particularly in smaller catchments. This is relevant especially in light of the increasing number of reservoirs becoming operational in the catchments during last decades (Svensson et al., 2005). However, such structures have not been implemented in our assessment due to the lack of suitable information on dams, artificial reservoirs and their current and future operation. As such, the actual magnitudes of the lowflow measures derived herein reflect more the conditions in undisturbed catchments. However, it can be argued that, unless considerable alterations in flow regulation take place to mitigate the severity of extreme low-flow conditions, results expressed in terms of relative changes in low flows are reasonably representative. LISFLOOD was calibrated using at least four years of historical river flow data in the period 1995-2002 in 258 catchments and sub-catchments distributed throughout Europe. For a more detailed description of the processes and equations of LISFLOOD, as well as of its calibration, we refer the reader to van der Knijff et al. (2010) and Feyen et al. (2007, 2008).

Prior to forcing the LISFLOOD model, the climate simulations were re-gridded to the $5 \mathrm{~km}$ LISFLOOD grid employing a nearest neighbor approach on the basis of the center points of the $25 \mathrm{~km}$ grid cells of the RCMs. The water use data were similarly re-gridded from their 5 arcmin grid to the LISFLOOD grid. The WaterGAP3 monthly (for irrigation) and annual (for the other sectors) water consumption data were equally distributed over the days in each month or year, respectively, and accounted for in LISFLOOD as a daily loss term. LISFLOOD was then run with a daily time step for a simulation period between 1961 and 2100. As such, for each experiment (climate ensemble member combined with or without water use) $140 \mathrm{yr}$ of daily discharges were produced at each river pixel. To analyze changes over this period, time slices of $30 \mathrm{yr}$ were considered, further herein referred to as control period (1961-1990), 2000s (1981-2010), 2020s (2011-2040), 2050s (2041-2070), and 2080s (20712100). For each period a flow duration curve (FDC) was derived in each river pixel from the $30 \mathrm{yr}$ simulated discharge time series. FDC represents the percentage of time that river flow is likely to exceed some specified value and has been used herein as the basis for the calculation of the low-flow indices detailed below.

\subsection{Indices of streamflow drought}

Various drought indices have been developed to monitor and quantify droughts. For an extensive overview on low-flow and drought indices and their derivation we refer the reader to Smakhtin (2001), Tallaksen and van Lanen (2004) and Mishra and Singh (2010). In this work we follow the approach of Feyen and Dankers (2009) and focus on two important aspects of a drought, namely magnitude and persistence through time.

Firstly, we analyze low flows through the magnitude of the river discharge, expressed here by the 7 day minimum flow (qmin) at several recurrence intervals. We apply a 7 day averaging to focus on the general behavior of streamflow dynamics and to cancel the day-to-day fluctuations in river flow, which are often arbitrary or artificial in low-flow periods (Tallaksen and van Lanen, 2004; Lehner et al., 2006). From the smoothed discharge series the annual minima are selected, through which a generalized extreme value (GEV) distribution is fitted using the maximum likelihood (ML) method (Gilleland and Katz, 2005). From the fitted GEV distribution qmin values for different return periods ranging between 2 and $100 \mathrm{yr}$ are derived in each river pixel.

Secondly, we consider the development in time of drought events by evaluating deficit characteristics of periods in which discharge stays below a threshold flow. Deficits can be evaluated in terms of their run duration (length of event) and severity (cumulative deficit or negative run sum) (Smakhtin, 2001). However, given the often strong correlation between drought durations and deficit volumes (Woo and Tarhule, 1994) and considering that the latter are a more effective measure of the magnitude of water shortage relevant for operational water management (Tallaksen and van Lanen, 2004), we focus only on deficit volumes (def). The threshold for evaluating deficits can be defined as a percentage of the mean flow or as an exceedance frequency of the FDC. We opt for the latter, such that everywhere in Europe discharge time series fall below the threshold an equal number of days, but allowing deficit volumes to vary according to location-specific conditions. As a balance between representing low-flow conditions and assuring sufficient events for extreme value fitting (Tallaksen et al., 1997; England et al., 2004; Fleig et al., 2006) we apply the $80 \%$ exceedance frequency of the FDC (further referred to as $Q_{80}$ ), as constant threshold. We note that for the future time slices, deficits are evaluated against the threshold from the control period (1961-1990). Using the ML method, in each river cell a generalized Pareto (GP) distribution was then fitted through the partial duration series of deficit volumes representing the shortfalls below the threshold. From the fitted distribution, deficit volumes for recurrence intervals ranging between 2 and $100 \mathrm{yr}$ were derived.

The selection of drought events with the threshold method using a daily time resolution is, however, plagued by two problems. Firstly, when in periods of prolonged low-flow conditions the flow shortly exceeds the threshold level, the large event is split in two or more smaller mutually dependent events. Secondly, shortfalls below the threshold of very short duration yield very small deficit volumes that may cause instability in the extreme value distribution fitting (Engeland et al., 2004; Tallaksen and van Lanen, 2004; Fleig et al., 2006). Tallaksen et al. (1997) evaluated three different pooling procedures to reduce the occurrence of minor events and reduce mutual dependency. On the basis of their results, and similar as for the low-flow indices described above, we apply a moving average (MA) procedure with a 7 day averaging window to the discharge time series prior to selecting the events, which removes minor droughts and pools mutually 
dependent droughts. As not all minor events were excluded after the 7 day MA procedure, in each river cell we additionally removed all events with a deficit smaller than $0.5 \%$ of the maximum deficit in that cell, following Zelenhasic and Salvai (1987).

\subsection{Streamflow regimes in Europe}

Streamflow regimes across Europe vary strongly due to the large variability in climatologic conditions and local factors that influence the hydrological response, such as the presence of aquifers, variations in soil properties and land cover. In regions with a cold climate, typically winter and summer droughts can be differentiated (e.g., Fleig et al., 2006; IPCC, 2012). In winter, most water is trapped as snow and ice, often resulting in the lowest flows seen throughout the year. Hence, by applying an annual analysis there is the risk that low flows in the frost-free season, originating from negative imbalances in precipitation, are not accounted for, or that the sample of events used for extreme value fitting find their origin in different physical processes. The latter also violates the underlying theory of frequency analysis, namely that the events are considered to be drawn from an independent and identically distributed (iid) random variable.

Following Hisdal et al. (2001) and Feyen and Dankers (2009) we distinguish between a nonfrost and frost season, where the latter is defined for each river pixel as the period of the year in which the monthly average temperature in the upstream area drops below zero in at least 23 out of $30 \mathrm{yr}$ (reference length of time slices). By averaging over the upstream area we avoid labeling river pixels as nonfrost when in large parts of the upstream catchment water is still stored as ice or snow. This is especially the case for downstream river reaches in areas with pronounced topography, such as for the major streams that drain from the Alps (e.g., Rhine, Rhone, or Po rivers). Thus, time series of daily discharges are split up in nonfrost and frost seasons according to the afore-mentioned criterion. Streamflow drought indices are estimated separately for each season. Note that for deficit volumes we use different $Q_{80}$ threshold values calculated from the FDCs corresponding to the respective season.

For intermittent and ephemeral streams the data series of annual minima may contain several zero values, hence discontinuous probability distribution functions need to be applied for inferring low-flow probabilities. Analysis of the LISFLOOD simulations showed, however, that for catchments with an upstream area larger than $1000 \mathrm{~km}^{2}$ the time series of annual minima did not contain any zero flow values, and thus can be considered to be perennial under current and future climatic conditions. We therefore limit the analysis to river basins with an upstream area exceeding $1000 \mathrm{~km}^{2}$, hereby excluding ephemeral rivers. Even if the latter (headwater and lower order streams) are particularly sensitive to climate change, as analyzed in a comprehensive review by
Brooks (2009), to be properly quantified they would require a finer hydro-geomorphological characterization than the one provided in the large-scale approach presented herein. Furthermore, we argue that river basins with an upstream area exceeding $1000 \mathrm{~km}^{2}$ are representative enough to explore the impact of climate changes on future hydrological droughts at continental scale.

\subsection{Uncertainty in low-flow projections}

\subsubsection{Climate uncertainty}

Climate models are the most robust tools available to generate consistent climate change projections. However, they are still a source of considerable uncertainties due to the incomplete, missing or incorrect representation of some physical processes and approximated parameterizations (e.g., Katz, 2002; Murphy et al., 2004; Déqué et al., 2012). One of the crucial issues emerging from recent studies (see, e.g., Christensen and Christensen, 2007; van der Linden and Mitchell, 2009) is that different climate experiments may still show large variations in the simulated variables, especially for precipitation. This may be translated to the impact models, often resulting in considerable climate-induced variability in impact estimates.

Model uncertainties can be partly resolved using an ensemble-based framework where simulations from different climate models are used to drive the impact assessment model. Projections based on a multi-model ensemble can be considered more indicative than projections produced by single models alone, as the multi-model average or median can be expected to outperform individual ensemble members, thus providing an improved "best estimate" projection (IPCC, 2007, Stahl et al., 2011; Gudmundsson et al., 2012). On the other hand, it should be noted that a multi-model ensemble, especially when the sample is relatively small, may still be affected by extreme or outlier ensemble members. Also, over the ensemble, errors in one process or parameterization may be compensated by errors in other processes or parameterizations (e.g., Murphy et al., 2007). The weighting of climate simulations as an approach to combining climate information is subject to considerable debate (e.g., Christensen et al., 2010; Coppola et al., 2010; Déqué and Somot, 2010). Any weighting method depends on subjective choices about the metrics and combining procedure into an overall weight for the individual models. Such factors will determine the spread in the climate and impact estimates and add an additional layer of uncertainty. Therefore, climate simulations of the different ensemble members have been equally weighted when summarizing the low-flow projections.

In order to address uncertainty related to climate change projections we first quantified the consistency in the projections of streamflow drought indices. Here "consistent" is interpreted as the agreement amongst the 12 ensemble 
members in terms of showing a decrease or increase in low-flow measure of at least $5 \%$ with respect to the control period.

The statistical significance of the changes for the projections of streamflow drought indices is evaluated by the use of Welch's $t$ test, assuming that the variances of the control period and the different time slices are not necessarily the same (Welch, 1947; see also Von Storch and Zwiers, 1999, p. 113). Here, the test statistic can be approximated with a normal $t$ distribution, where the appropriate degrees of freedom are estimated from the data. If the resulting $p$ value is smaller than a predefined significance level, e.g., $5 \%(\alpha=0.05)$, the ensemble mean in the future time slice is said to be significantly different from that in the control period given the climate uncertainty.

\subsubsection{Extreme value fitting uncertainty}

The aim of extreme value (EV) analysis is to find a parametric model for the tail of the data generating process, then to fit this model to the extreme observations and use it for extrapolation beyond the observed data. Extreme value modeling typically faces the problem of data scarcity, or that the fitting is based on a relatively small number of observations. This introduces uncertainty in the estimation of the return levels that depends on the quantity of data in relation to the degree of extrapolation. Here this uncertainty has been appraised by applying the profile-likelihood method (Coles, 2001) on the return levels of the GEV and GP distributions and estimating the corresponding $95 \%$ confidence intervals. The profilelikelihood has proven to be more robust and able to better capture the usual asymmetric nature of the confidence intervals than other conventional methods (e.g., delta method) (Coles, 2001; Beirlant et al., 2004).

We note that recent studies have shown that hydrological uncertainty may further increase the variability of projections in water resources (Gudmundsson et al., 2012; Hagemann et al., 2013), in particular in the low-flow spectrum as suggested by the considerable discrepancy between large-scale hydrological models in the evaluation of drought propagation (Van Loon et al., 2012). Hydrological components may, however, be differently affected by modeling uncertainties. For instance, Hagemann et al. (2013), using multiple global climate and hydrology models, suggests that uncertainty in the projected changes in evapotranspiration is largely dominated by the spread due to the choice of the hydrological models, whereas uncertainty in runoff changes mainly originates from the choice of the climate model. In contrast, other studies have shown the limited relevance of hydrological uncertainty compared to uncertainty arising from climate models (e.g., Wilby, 2005; Najafi et al., 2011). Even if hydrological modeling could potentially introduce additional sources of uncertainty in the projections of streamflow droughts, an attempt to account for the hydrological uncertainty is beyond the scope of our analysis. Moreover, the quantification and

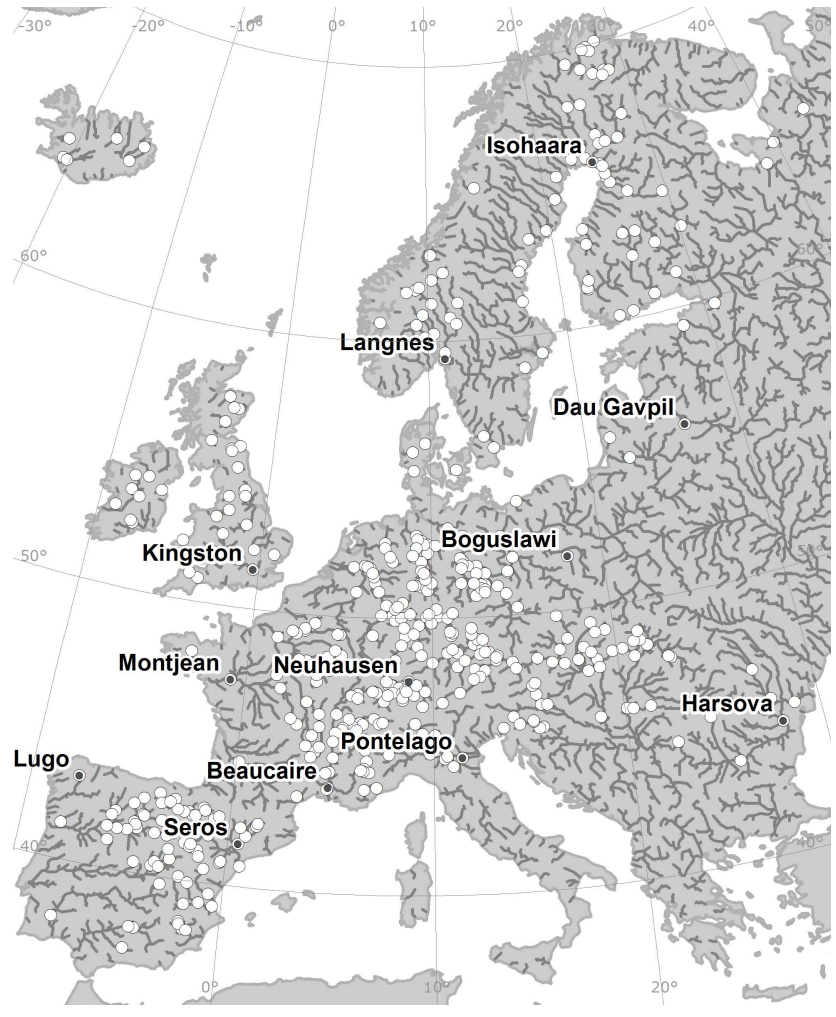

Fig. 1. Location of the 446 gauging stations used to evaluate simulated streamflow drought indices. Filled black circles show validation stations used in Figs. 5, 6 and 12.

modeling of environmental, social, and policy drivers of water use - such as population dynamics, land use changes, and agricultural, industrial, energy and environmental policies as well as economic and technological developments, are inherently uncertain (Kok et al., 2011). Therefore actual water consumption could deviate from the SCENES projections used herein.

\section{Results and discussion}

\subsection{Validation of low-flow simulations}

A large set of 446 gauging stations across Europe (see Fig. 1) - for which long enough daily data time series were available ( $30 \mathrm{yr}$ of records for the majority of stations) - was employed to validate simulated low-flow indices for the control period (1961-1990). Daily discharge values have been collected within the ECA\&D project (http://eca.knmi.nl) and by the Global Runoff Data Centre (GRDC), CEDEX-IEH Banque HYDRO and ARPA Emilia Romagna. A preliminary screening procedure was implemented to avoid the inclusion of stations with ephemeral conditions and multi-year observational gaps. The validation network covers a wide range of hydroclimatic regimes in Europe and varies in the size of contributing upstream areas from ca. 1000 to ca. $810000 \mathrm{~km}^{2}$. 
As shown in Fig. 1, the validation stations are not evenly distributed across Europe, with a high density of stations located in western and central parts of Europe and hardly any in Italy and southeastern Europe. At 338 stations the number of years with a frost season in the control climate was at least 23 out of 30; hence they were used for validation in both the nonfrost and frost season analysis.

Control climate simulations do not reproduce the historical weather of the 1961-1990 period, but only the average climate conditions. This does not allow a day-to-day or event-to-event comparison. Instead, we evaluate the accuracy of the LISFLOOD simulations by comparing observed and simulated low-flow indices over 1961-1990 through statistical measures. More specifically, we employ model efficiency (EF), and percent bias (PBIAS), defined as

$\mathrm{EF}=1-\left[\sum_{i=1}^{N}\left(Y_{\mathrm{obs}, i}-Y_{\mathrm{sim}, i}\right)^{2} / \sum_{i=1}^{N}\left(Y_{\mathrm{obs}, i}-\bar{Y}_{\mathrm{obs}}\right)^{2}\right]$,

PBIAS $=100 \cdot\left[\sum_{i=1}^{N}\left(Y_{\mathrm{sim}, i}-Y_{\mathrm{obs}, i}\right) / \sum_{i=1}^{N} Y_{\mathrm{obs}, i}\right]$,

where $Y_{\mathrm{obs}, i}$ and $Y_{\mathrm{sim}, i}$ are the observed and simulated lowflow index at station $i=1, \ldots, N=446$, respectively, and the horizontal bar denotes averaging over all stations. EF determines the relative magnitude of the simulated error variance compared to the observed data variance. It ranges between minus infinity and 1.0, with higher values for increased model performance. PBIAS measures the average tendency of the simulations to be larger or smaller than observations. It ranges from -100 to +100 with low-magnitude values (close to 0 ) indicating accurate model prediction, whereas positive (negative) values indicate overestimation (underestimation). Note that the $Q_{80}$ threshold for the analysis of deficit volumes is separately calculated for the observed and simulated time series, which implies that the validation is based on relative differences in deficit volumes.

Figure 2 presents the performance of the 12 ensemble members to reproduce average annual 7 day minimum flows in the control period. Results show a good performance across the climate simulations with EF values ranging between 0.81 and 0.95 . Two common features can be observed for all members of the ensemble. Firstly, at some stations the simulated minimum flows deviate strongly from those derived from observations, a behavior that is more pronounced with decreasing catchment size (note that lower (bigger) discharges generally correspond to smaller (larger) catchments). This relates to multiple sources of uncertainty that are more dominant in small basins. These include, among others: intrinsic limitations of RCMs to reproduce small-scale processes; conceptual approximations in the LISFLOOD model, its input data and parameterization; not fully accounting for reservoirs/lakes and flow regulation in the modeling setup; and measurement errors at river gauging stations. The lower model performance for smaller catchments implies that future projections of changes in low-flow conditions presented herein should be interpreted more cautiously compared to those obtained for larger catchments. We also note that by coupling offline RCM simulations with the hydrological model, as well as by correcting the bias only in temperature and precipitation, the energy and water balance are not necessarily preserved. Notwithstanding the latter, Rojas et al. (2011) showed the strong improvement in LISFLOOD performance after bias correcting temperature and precipitation.

Secondly, there is a general tendency to underestimate observed minimum flows, as expressed by the negative values of PBIAS (ranging between -13 and $-40.5 \%$ ). This is most likely related to the underestimation of the low-end percentiles of the bias corrected precipitation, and a potential overestimation of the number of dry days obtained from the fitting of the transfer functions (Dosio and Paruolo, 2011; Rojas et al., 2011). The omission of reservoirs in the hydrological simulations may additionally contribute to the underestimation of the modeled streamflow drought conditions.

Figure 2 also shows that models with a large bias do not necessarily show a low performance based on model efficiency. This suggests that different ensemble members may provide higher accuracy with respect to simulating different aspects of the low-flow spectrum, which reinforces the idea of a multi-model framework as the basis for streamflow drought impact assessment due to climate change. This also supports the findings of Lenderink (2010), who explored different metrics of extreme daily precipitation to conclude that there is no metric that guarantees an objective and precise ranking or weighting of climate models.

Figure 3 presents the ensemble-averaged performance for different low-flow indices, where panel 3 a corresponds to the average performance of the individual members presented in Fig. 2. Noteworthy is the strong negative bias for the average deficit volumes (Fig. 3b) compared to average minimum flows (Fig. 3a). This implies that LISFLOOD driven by the climate simulations tends to underestimate flow deficits (or less severe droughts), but also, albeit to a lesser extent, minimum flows (or more severe droughts). What seems a conflicting discrepancy in bias between the simulationand observation-based statistics (i.e., model simulates less vs more severe droughts depending on index), suggests that the underestimation of the low-end percentiles of the bias corrected precipitation and the overestimation of the number of dry days have a relatively higher impact on the lowend percentile range $Q_{80}-Q_{99}$ than on more extreme low flows. This seems also corroborated by the absence of a similar systematic negative PBIAS for both minimum flows and deficit volumes in the validation analysis performed by Feyen and Dankers (2009), who did not apply any bias correction procedure on the climate signal. 

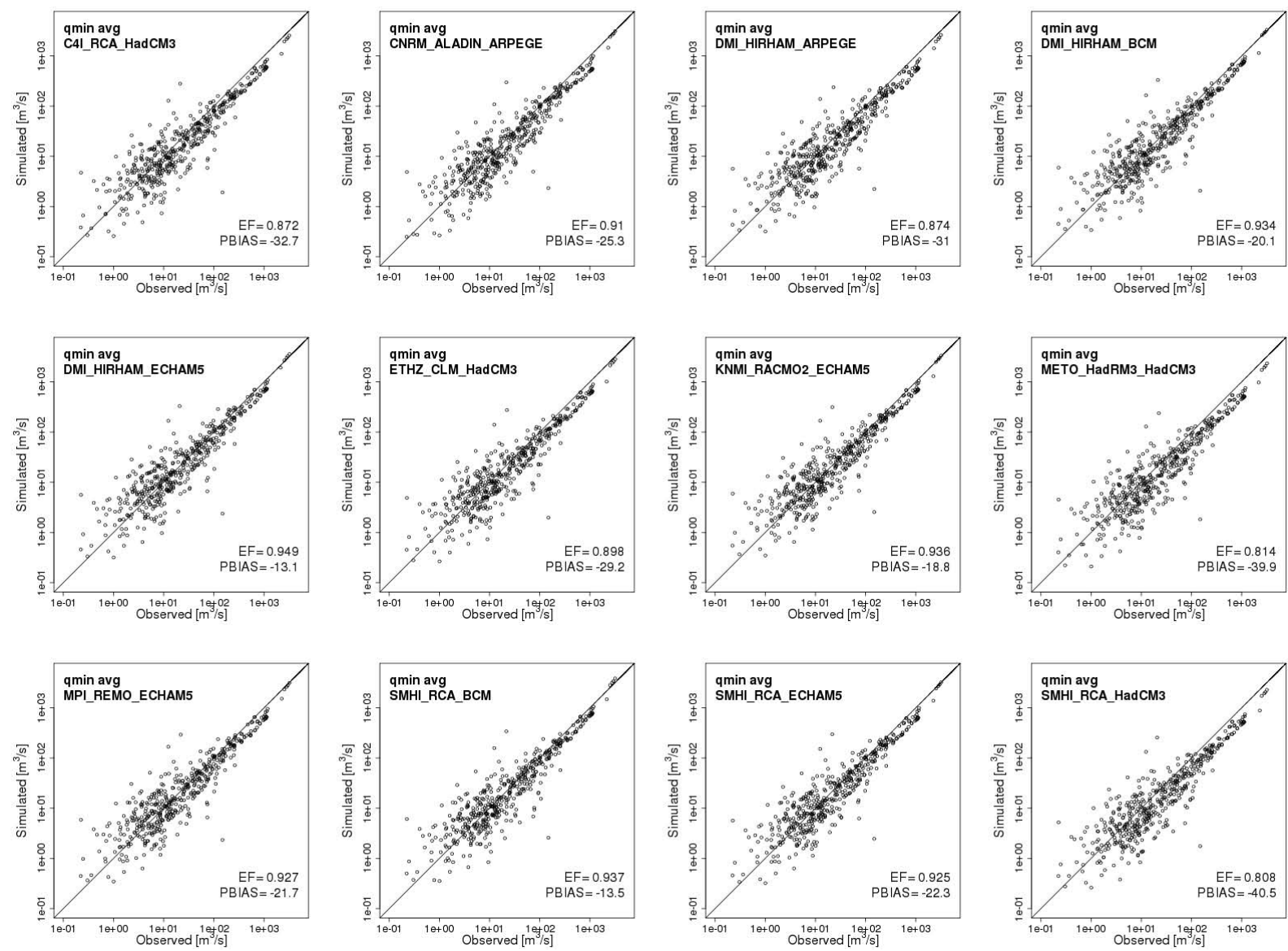

Fig. 2. Observed versus simulated average annual 7 day minimum flows for the control period (1961-1990) at each of the 446 stations depicted in Fig. 1 based on the hydrological simulations driven by the 12 climate experiments listed in Table 1.

A comparison between the statistics of the fitted extreme value distribution (here exemplified by minimum flows and deficits with a $20 \mathrm{yr}$ recurrence interval) shows nearly equally good performance for the minima and deficits (Fig. 3c, d). The decreases in PBIAS observed for fitted extreme values with respect to the averages may be explained by the fact that the former includes an optimization process that minimizes discrepancies between observed and simulated values, thus reducing the bias. High values of EF confirm that LISFLOOD simulations are fairly robust in capturing the statistics of extreme streamflow droughts occurring in the nonfrost season.

In Fig. 3 (panels $3 e$ and 3f) it can also be seen that LISFLOOD driven by control climate simulations has problems in reproducing runoff and base flow in the frost season, resulting in a larger tendency to underestimate the low-flow indices in comparison to the nonfrost season. This is due to a combination of several factors, including (1) conceptual and parameter errors in the snow and frost modules of LISFLOOD that affect drainage in the cold season; (2) uncertainties in the observed winter precipitation (Goodison et al., 1998; Yang et al., 2001) used in the calibration of the hy- drological model that may have resulted in an incorrect parameterization of the groundwater reservoir; (3) too low temperatures during intermittent melt events, resulting in more water that remains stored as snow and less base-flow generation; and (4) not properly accounting in the LISFLOOD setup for storage release from reservoirs to guarantee minimum flow requirements, for example, for hydropower production. This may also induce artificially higher thresholds $\left(Q_{80}\right)$ than those derived from the simulated flow duration curve, yielding at many stations larger observed deficit volumes compared to those simulated, especially under severe drought conditions.

From the validation, we can conclude that for the nonfrost season, LISFLOOD driven by a multi-model ensemble of bias-corrected regional climate simulations is able to reproduce streamflow droughts, expressed by the average annual minima and deficits (Fig. 3a, b) and the corresponding $20 \mathrm{yr}$ events (Fig. 3c, d), reasonably well across the wide range of climatic and hydromorphological conditions of Europe. For the frost season, LISFLOOD simulations are less reliable due to the reasons described above, hence these results should be interpreted more cautiously. Having quantified the 

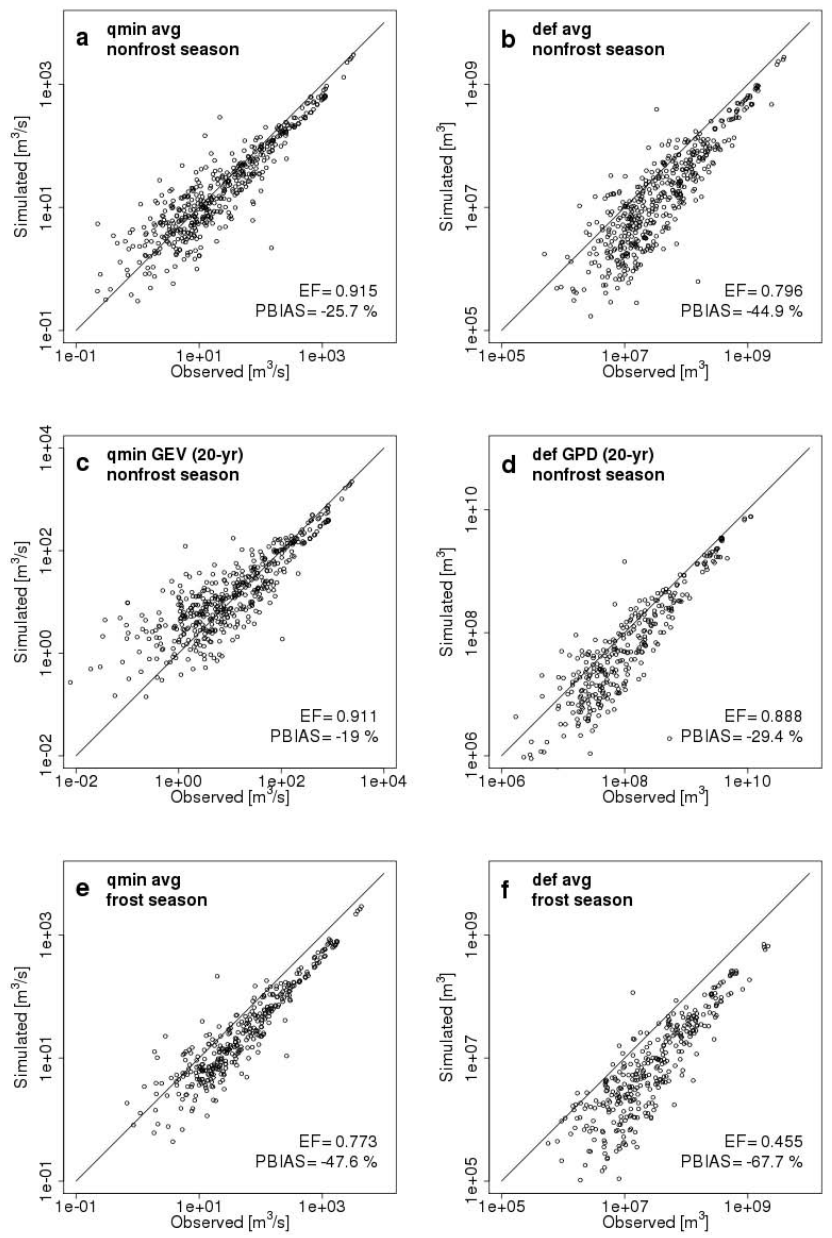

Fig. 3. Observed versus ensemble-averaged simulated streamflow drought indices for the control period (1961-1990) at each of the 446 stations depicted in Fig. 1.

LISFLOOD capabilities in simulating low flows, we derive streamflow drought indices of the future time slices $(2000 \mathrm{~s}$, 2020s, 2050s, 2080s) for both nonfrost and frost seasons.

\subsection{Changes in meteorological forcing and water consumptions}

To better understand the processes affecting future low-flow characteristics across Europe we first summarize the projected changes in the main driving climatic variables. Figure 4 shows for Europe the ensemble-average changes by the 2080s compared to the control climate (1961-1990) in temperature and precipitation for the nonfrost and frost seasons. Because streamflow at a given location depends on the hydroclimatological conditions over the upstream river basin, these maps show average changes over the upstream area that contribute flow to that location rather than the change at the grid cell itself. Figures 5 and 6 (top 2 rows) present ensemble-average alterations in these variables throughout
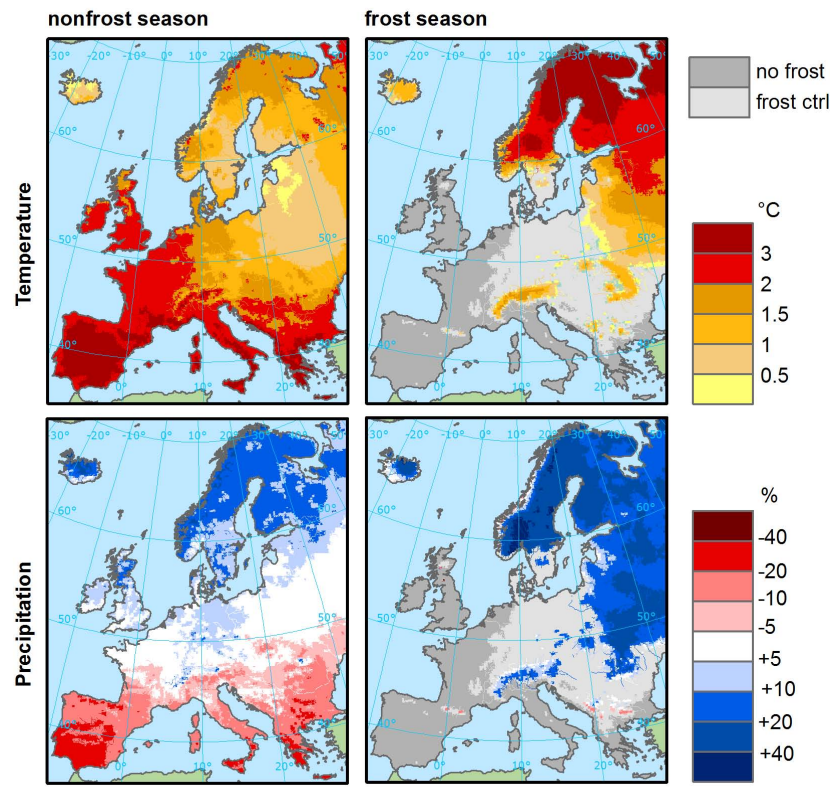

Fig. 4. Ensemble-averaged changes in average temperature (top row) and precipitation (bottom row) between 2080s and control period for nonfrost (left column) and frost (right column) seasons. The change at each location reflects the average change over the upstream area contributing flow to that location. In the frost season panels, areas shaded in light gray represent regions with a frost season in the control climate and without a frost season in the ensemble-average scenario climate, while dark gray areas indicate regions with no frost season both in the control and scenario periods.

the year at a selection of stations that span the range of climatic and hydrological conditions in Europe (see Fig. 1).

Figure 4 shows that temperature in the nonfrost season is projected to increase all over Europe, with the strongest warming (up to $4^{\circ} \mathrm{C}$ increase by the end of this century) in southern parts of Europe. This is confirmed by the station plots in Figs. 5 and 6, where the increase in summer temperature at southern stations (Fig. 6, stations Beaucaire, Pontelago, Lugo and Seros) is more pronounced than at those located further north (Fig. 5, stations Langnes, Isohaara and Dau Gavpil). In cold regions, the rise in temperature during the frost season is projected to be higher than in the nonfrost season (e.g., stations Langnes, Isohaara and Dau Gavpil). This agrees with other works based on different RCMs (e.g., Christensen et al., 2007), which showed the strongest increase in temperature during winter for northern parts of Europe. Due to warming, the frost season, defined here as the period in the year for which in at least 23 out of $30 \mathrm{yr}$ the monthly average temperature drops below zero, will shorten (e.g., stations Langnes, Isohaara, Dau Gavpil and Neuhausen), or disappear completely (e.g., stations Boguslawi and Harsova). Consequently, the spatial extent of areas with a frost season in the control climate, shaded in light gray in Fig. 4, is projected to shrink (shift to higher latitudes 

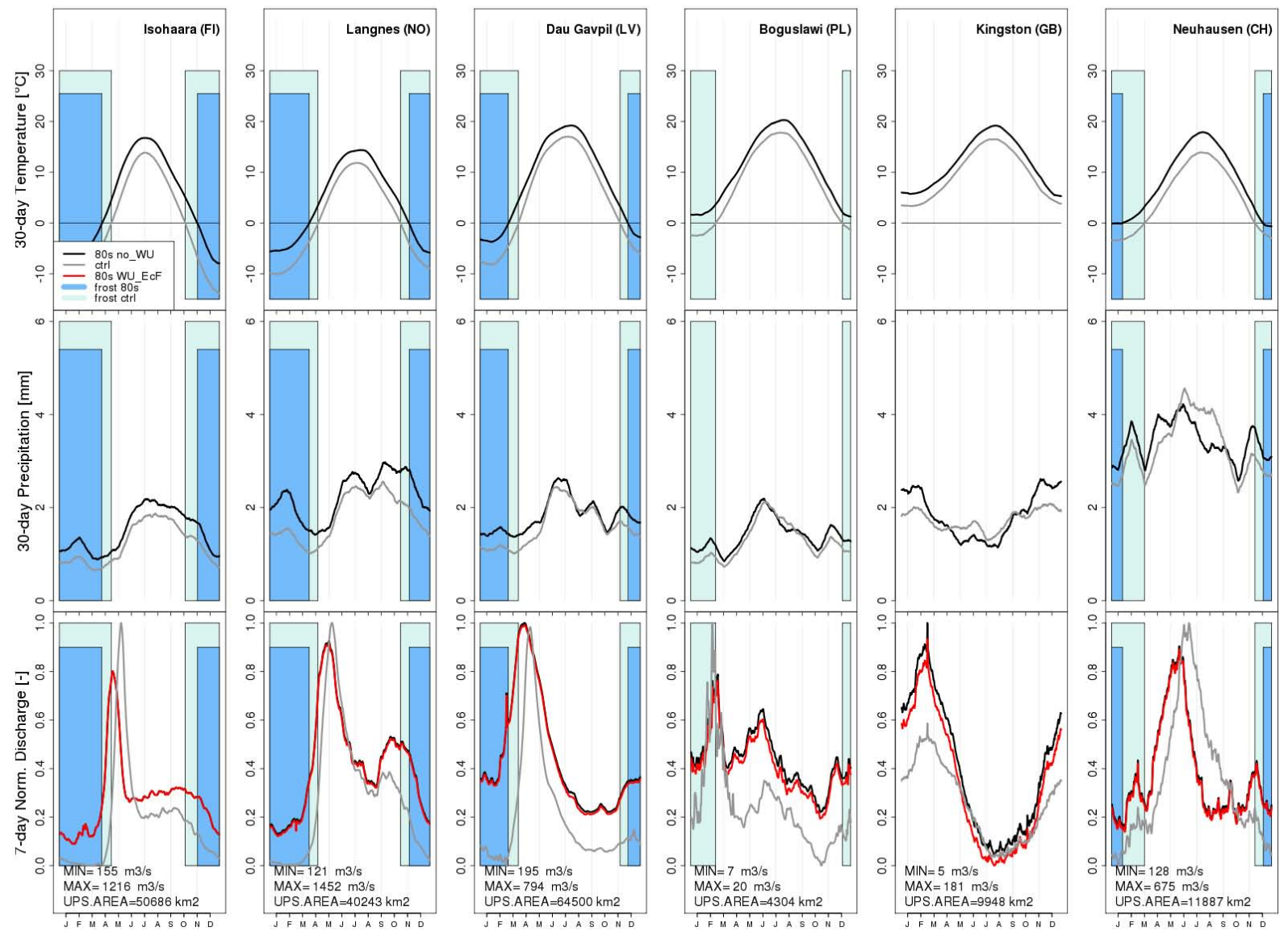

Fig. 5. Inter-annual dynamics in temperature (top row), precipitation (middle row) and 7 day average streamflow (bottom row) at a selection of stations (see Fig. 1) in the control period (light gray lines) and 2080s (black line). Temperature and precipitation reflect 30 day upstream averages. The red line for streamflows (bottom row) reflects the scenario accounting for water use. Blue shaded areas indicate the frost season in both periods (control as light blue, 2080s as dark blue).

and altitudes) considerably in the course of the 21st century. The absence of a permanent frost period due to global warming will strongly affect the hydrological cycle and ecosystem functioning in these regions.

Average precipitation in the nonfrost season is projected to decline in southern Europe, with decreases as high as $30 \%$ in the most southern regions, to a rise of 10-20\% in northern Europe, and to remain relatively stable in a transition zone in between. Comparison of the stations plots in Fig. 6 shows that in the most southern parts of Europe (see stations Lugo and Seros) drying is much stronger in spring compared to summer, whereas further north (see stations Montjean and Beaucaire, Ponte Lago) equally strong reductions are observed in summer precipitation. Note that the average maps over the nonfrost season may mask some of the inter-annual changes. At Kingston station (Fig. 5), for example, average precipitation is projected to slightly increase, but summer precipitation will decrease. In the frost season average precipitation is projected to strongly increase over most parts of northern Europe (e.g., stations Langnes, Isohaara and Dau
Gavpil, Neuhausen in Fig. 5), which is in line with other studies using different climate models and emission scenarios (see e.g., Christensen and Christensen, 2007; Räisänen and Eklund, 2012).

Figure 7 shows total annual water withdrawals aggregated to the river basin for the control period and the corresponding expected changes in the 2050s according to the EcF scenario from SCENES. This figure summarizes current and future water use to better capture possible human-induced intensification of streamflow droughts. Most intense water abstractions can be observed in the United Kingdom, the Benelux countries, Germany and northern Italy with more than $100 \mathrm{~mm}$ of annual water consumption. Lower consumption $(<25 \mathrm{~mm})$ is observed in northeast Europe, western France and to some extent Hungary as well as Croatia. The Iberian Peninsula and countries of eastern Europe show intermediate total water withdrawals. Water withdrawals are expected to increase in the 2050 s by more than $50 \%$ in western, eastern and northern Europe mainly due to the growing cooling-water demand of the thermoelectric power industry 

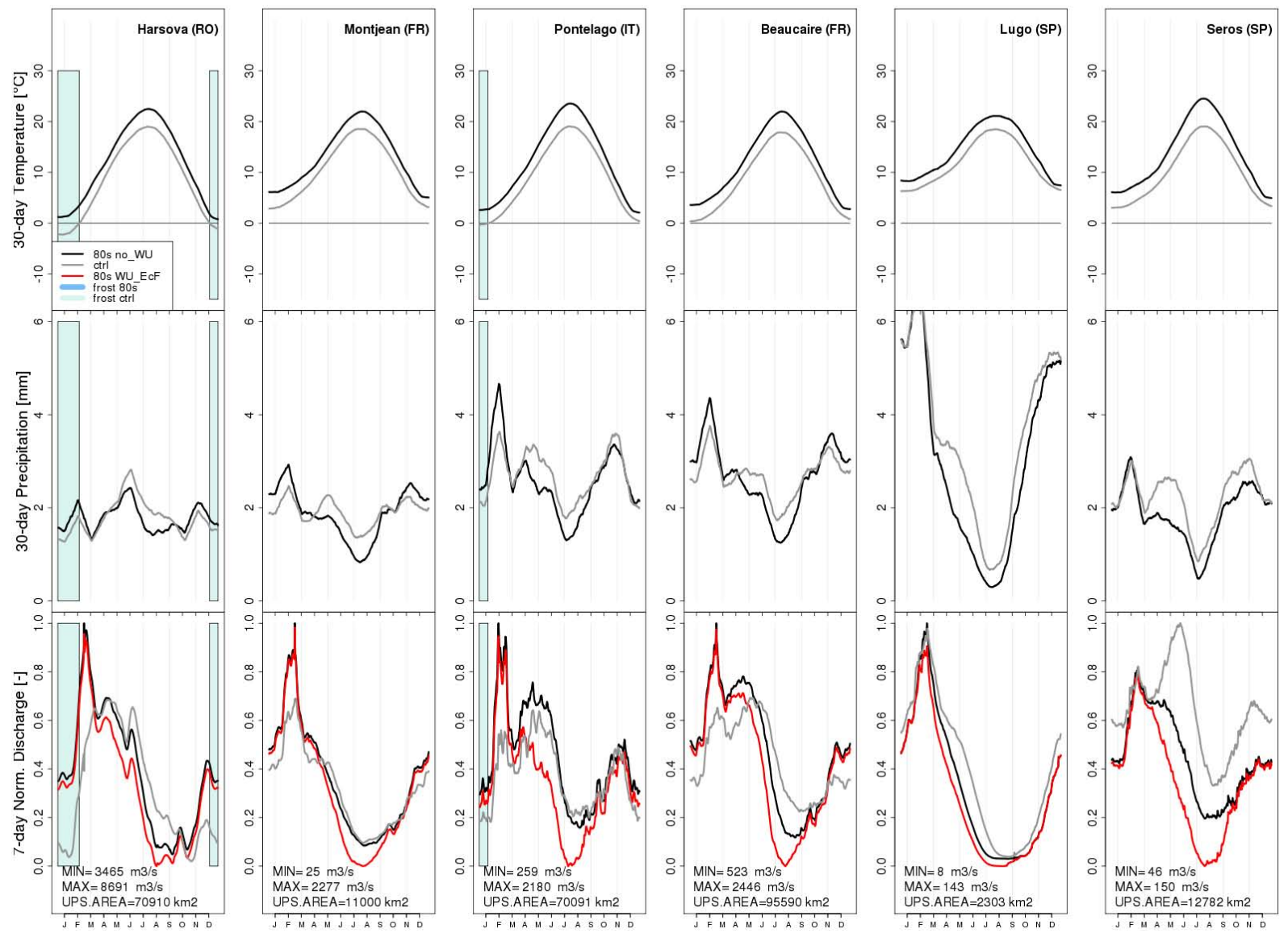

Fig. 6. As Fig. 5, for different stations.

and to increasing manufacturing (Flörke et al., 2011). At the same time, irrigation water requirements will play a major role in the northern Iberian Peninsula and northern Italy due to an intensification of crop production in combination with increasing temperatures induced by climate changes, and will lead to an increase of ca. $25 \%$ in total water abstractions. Slight decreases in future total annual water withdrawals can be observed in some river basins in Denmark, southern Iberian Peninsula, southern Italy and Greece. In southern Iberia this is likely a result of the expected reduction in annual irrigation water consumption. Additional details on changes in water consumptions for the different sectors can be found in Flörke et al. (2011).

\subsection{Projections of future streamflow droughts}

\subsubsection{Frost season}

The bottom rows in Figs. 5 and 6 show how the changes in meteorological forcing affect the streamflow dynamics across Europe. In stations with a frost season (e.g., stations Langnes, Isohaara, Dau Gavpil, and Neuhausen in Fig. 5), low flows in this period are projected to augment considerably, and hence winter droughts to become less severe. In warmer and wetter winters, a smaller portion of precipitation will be temporarily stored as snow or ice, resulting in increased flows in the cold season. This is in line with the findings by Räisänen and Eklund (2012) of a decrease in long-term mean snow water equivalent throughout the 21 st century in northern Europe.

The magnitude of change in the low-flow spectrum in the frost season is positively correlated with the magnitude of change in precipitation and temperature in the upstream basin. However, streamflow droughts also depend on hydroclimatologic conditions prior to the onset of the frost season, especially for extreme events as they reflect imbalances in water availability over longer time spans. In northeastern regions summer and to a lesser extent also autumn precipitation is projected to rise, resulting in a relatively larger subsurface storage at the start of the frost season. The extreme or very rare minimum flows are therefore expected to show a relative increase that is less pronounced than for more moderate low-flow conditions. These findings are fully consistent with the results of Feyen and Dankers (2009). Given that droughts during the cold season will pose considerably less serious problems, the further analysis focuses only on the nonfrost season. 


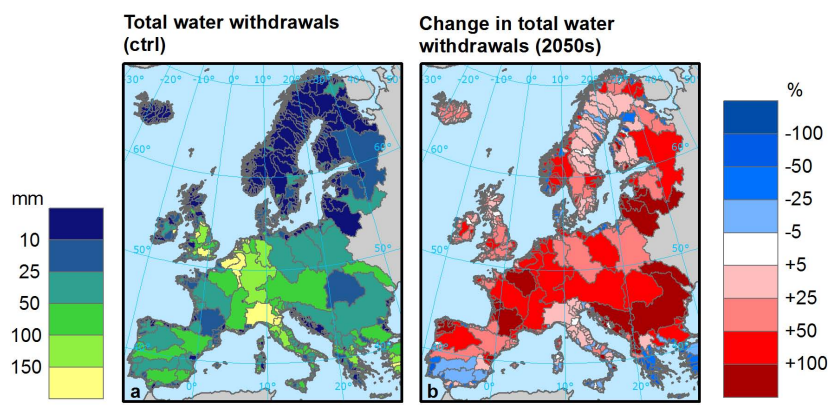

Fig. 7. Total annual water withdrawals aggregated to river basin scale for the control period (a) and the corresponding expected changes in the 2050s according to the EcF scenario from the SCENES project (b).

\subsubsection{Future streamflow minima in the nonfrost season}

For the nonfrost season, changes in 7 day minimum flows with recurrence intervals ranging from 2 up to $100 \mathrm{yr}$ were derived from the GEV distributions fitted through the annual minima series for the control and future time slices. Figure 8 (left column) shows for river pixels with an upstream area larger than $1000 \mathrm{~km}^{2}$ the changes in 7 day minimum flows (qmin) with $20 \mathrm{yr}$ recurrence intervals between the control and the four scenario periods. A reduction (augmentation) in minimum flows indicates increasing (decreasing) drought hazard and is displayed in red (blue) color in Fig. 8.

Hardly any changes in minimum flows can be detected between the control period and 2000s in part due to the $10 \mathrm{yr}$ overlap between the two time slices. By the 2020s, the most southern areas of Europe (Iberian Peninsula and southeastern Balkans) first start to see a reduction (10-20\%) in minimum flows. Progressing further in time, streamflow droughts in the south will gradually intensify and the areas negatively affected will expand further north, covering most of southern and western parts of Europe by the end of this century. The Iberian Peninsula, Italy, and the Balkan region will be most affected, with reductions in minimum flows of up to $40 \%$ by the 2080s, but also France and to a lesser extent the United Kingdom, Ireland and Belgium will experience lower minimum flows.

Lower minimum flows in future time slices result from the combined effects of reduced precipitation and increased evaporative demands with higher temperatures (e.g., Fig. 6, stations Lugo, Seros and Beaucaire). Actual evapotranspiration rates, however, are not necessarily higher, as they may be limited by lower soil and subsurface storage. Similar changes in streamflow droughts have been detected in southern parts of Europe by Lehner et al. (2006) and Feyen and Dankers (2009), even if they utilized different emission scenarios and climate simulations.

Although not shown here, the large spatial pattern of changes in Fig. 8 is similar for minimum flows at other return periods. However, in some regions (United Kingdom,
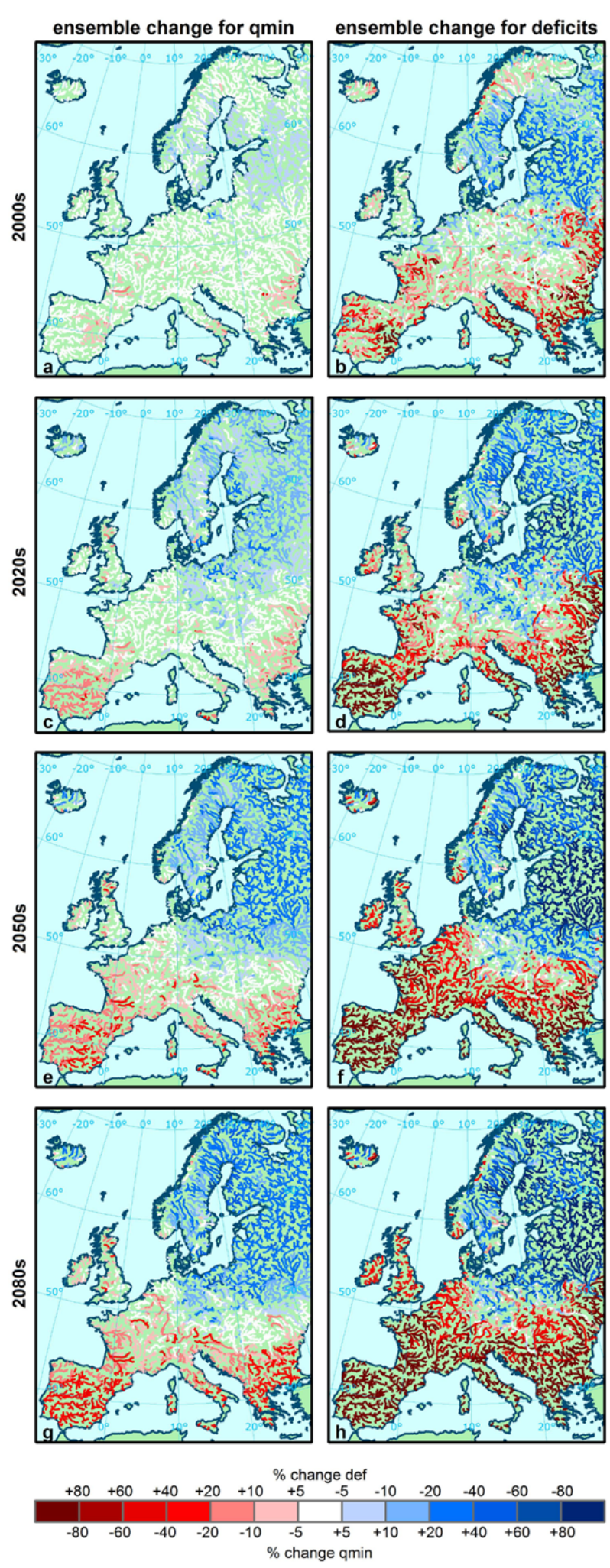

Fig. 8. Ensemble-average change in the $20 \mathrm{yr}$ return level minimum flow (left) and deficit volumes (right) due to only climate change between the corresponding time slices and the control period (19611990). 
Germany, Benelux, France, northern Italy and eastern parts of Europe) the reductions in minimum flows are relatively more severe for smaller return periods. This relates to the projected changes in the seasonality of precipitation. These regions will experience strong reductions in precipitation in summer and a less important decline in autumn, whereas precipitation will increase strongly in winter and mildly in spring (see e.g., stations Kingston, Beaucaire, Montjean and Pontelago in Figs. 5 and 6). Droughts in these regions are typically a summer or autumn phenomenon. Minimum flows with relatively short recurrence intervals, which reflect the water balance in the preceding months, are strongly impacted by the pronounced decrease in summer and autumn precipitation. The rarer events, on the other hand, reflect imbalances in precipitation over longer time spans, in which the reduced precipitation input over summer and autumn is counterbalanced by increased subsurface storage at the start of the summer season due to elevated precipitation amounts in winter and spring.

In northern parts of Europe an opposite signal is observed in the non-frost season and minimum flows prevalently increase (or become less severe) in time. Scandinavia and the Baltic countries will experience a general increase in $20 \mathrm{yr}$ minimum flows of up to $20 \%$ - in some inland tributaries up to $40 \%$ - by the end of the 21 st century. This is a result of the increase in precipitation that outweighs the effects of increased evapotranspiration demands with higher temperatures. Here the change to less severe droughts is more pronounced for rarer events due to the considerable increase in precipitation during the frost season, which after melting of snow in spring yields larger volumes of water stored in the subsurface at the start of the summer season. In some high-latitude areas, however, the projected rise in winter precipitation may not necessarily result in thicker snowpacks, which in combination with earlier snowmelt may result in relatively stable minimum flows in the frost-free season (e.g., some southern parts of Sweden and along the west coast of Norway).

\subsubsection{Future streamflow deficits in the nonfrost season}

Changes in 7 day streamflow deficits with return periods ranging between 2 and $100 \mathrm{yr}$ were obtained from the fitted GP distributions for deficit volumes in both the control and scenario time slices. We present changes in $20 \mathrm{yr}$ deficits (def) (Fig. 8, right column) for river pixels with upstream catchment size exceeding $1000 \mathrm{~km}^{2}$. Note that in this case red colors indicate an increase in flow deficits, which implies more severe shortfalls below the threshold ( $Q_{80}$ of control period) or more severe droughts.

In the nonfrost season flow deficits are projected to become more severe in most of Europe, except in northern and northeastern regions. In many regions of the Mediterranean - including the Iberian Peninsula, Italy and the Balkans - as well as parts of eastern Europe - including Bulgaria and Ro- mania - $20 \mathrm{yr}$ deficit volumes are expected to increase by $50 \%$ by the 2020 s. These regions will experience continued drought intensification up to the end of the century, with deficit volumes (below $Q_{80}$ of the control period) increasing by up to $80 \%$ by the 2080 s. From the 2050 s onwards most of France, the Netherlands, Belgium, United Kingdom and the Alpine regions will also be prone to more severe streamflow deficits (increases between 20 and 50\%). Although not shown here and in agreement to what was observed for the minimum flows, events with shorter recurrence intervals show stronger increases in deficit volumes (mainly in southwestern parts of Europe). It should be noted, however, that the extrapolation error when fitting the extreme value distribution beyond the length of the time series increases with recurrence interval. Hence, projections for higher return periods are more prone to uncertainty, which also explains the somewhat more scattered pattern in the changes of deficit volumes for higher return periods in some regions.

In northeastern Europe, including the Baltic countries, flow deficits in the nonfrost season show a declining trend, with reductions in deficit volumes of up to $60 \%$ and more by the end of this century. Northwestern parts of Europe display a decreasing trend in deficit volumes, but locally (e.g., along the Norwegian west coast, areas in southern Sweden) the changes show higher spatiotemporal variability with sparse rivers showing an opposite tendency in the signal of change. This mixed pattern is due to the combined effects of a general increase in precipitation and reduced snowmelt contribution caused by less accumulation of snow in winter. Depending on the relative magnitude of these processes in future time slices, streamflow deficits in this region may either become more or less severe.

A comparison of the projected changes in deficit volumes (Fig. 8, right column) with those in minimum flows (Fig. 8, left column) for the different time slices shows that the relative alterations in flow deficit volumes are more pronounced than those in the magnitude of minimum flows. Some regions where minimum flows are projected to stay more or less stable or slightly increase may even show increasing trends in deficit volumes (e.g., northern France, Benelux, UK and Ireland, Hungary and sub-regions of Romania). This suggests that at an intra-annual scale streamflow droughts will develop longer in time, or become more persistent and that the flow spectrum in the range of $Q_{90}-Q_{70}$ is more affected than very extreme low flows. This implies that streamflows in the scenario's climate may show more frequent and intense shortfalls below the $Q_{80}$ threshold of the control period, even when the extreme minimum remain relatively stable. Again, this is due to the fact that extreme low flows are affected by hydroclimatologic conditions over longer time windows, in which the negative impact of drying in the nonfrost season is partly offset by wetter winters. More frequently occurring low-flow conditions, on the other hand, reflect short-term imbalances in precipitation and are thus largely determined by the strong precipitation reduction in the summer season. 


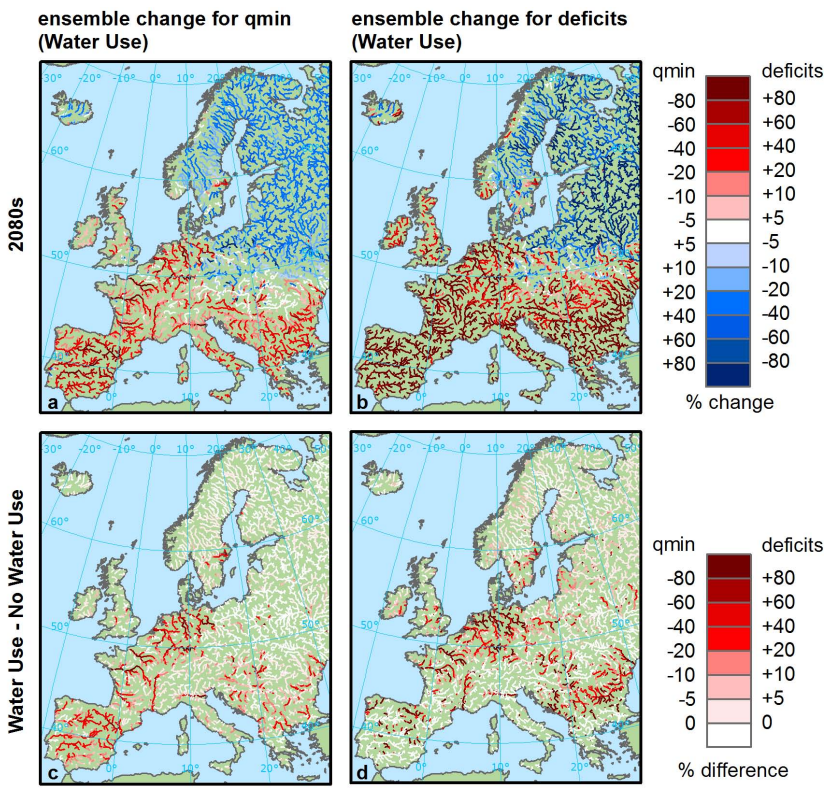

Fig. 9. Ensemble-average change in $20 \mathrm{yr}$ return level minimum flow and deficit volumes due to climate change and water consumption between the 2080s and the control period (top row) and corresponding differences with ensemble-average changes driven only by climatic drivers (bottom row).

Similarly, rarer deficit volumes (i.e., with higher recurrence intervals) are therefore less affected at midlatitudes.

\subsubsection{Impact of water consumption on streamflow droughts in the nonfrost season}

The results described above only show the effect of climate change on low-flow characteristics. The impact of increased water consumption on low-flow characteristics is presented in Fig. 9, which shows the ensemble-average change between the 2080s and the control period in $20 \mathrm{yr}$ minimum flows and deficit volumes when accounting for both climate change and water consumption (Fig. 9a, b). It is worth noting that the 7 day-average streamflow accounting for both climate change and water use is also included in Figs. 5 and 6 as a red line in the bottom row panels. Note that to account for water consumption, LISFLOOD was coupled on a daily time step with WaterGAP3 for the whole simulation period 1961-2100, hence the changes in low flows with respect to the control period reflect the combined effects of alterations in climate and consumptive water use. The bottom panels in Fig. 9 show for each drought index the difference between the ensemble-average changes driven by changes in climate and water use and those accounting only for the climatic ones for the 2080s.

Intensive water consumption as projected by the EcF scenario will further aggravate streamflow droughts in many regions of Europe. It will negatively affect both minimum flows and deficit volumes in central, western and eastern Europe due to the projected increases in water abstractions (compare with Fig. 7). In some regions where no or slightly positive changes in low-flow conditions are induced by climate change, increasing water consumption will reverse this trend and lead to more severe streamflow droughts. This behavior is most notable in the Benelux countries, western Germany, northwestern France (see station Montjean in Fig. 6), and localized parts in the United Kingdom (see station Kingston in Fig. 5), and in central and eastern European countries (Slovakia, Czech Republic, Hungary and Romania). Water use abstraction will exacerbate minimum low-flow conditions by ca. 10-30\% over the Mediterranean regions, especially where maximum rates of seasonal water demand of irrigated crops overlaps with drier periods (see e.g., stations Seros, Lugo, Ponte Lago and Beaucaire in Fig. 6). This suggests that even in front of a relative reduction in total annual water abstractions (compare with Fig. 7), the combined effects of alterations in climate and human water consumption will strongly aggravate streamflow drought conditions. In regions with a positive effect of warming on low-flow conditions, such as the Scandinavian Peninsula and Baltic countries, intensive water use may reduce future low flows, but not sufficiently to offset the positive effect.

\subsection{Uncertainty in projections of streamflow droughts}

Figure 10 presents the consistency amongst the 12 ensemble members in projecting a decrease (left panels) or increase (right panels) in minimum flows in future time slices with respect to the control period. Similar patterns are found for deficits and are not shown here for brevity. For the 21st century, the majority of hydrological simulations depict consistently increasing streamflow drought conditions over the Iberian Peninsula, France, Italy, the United Kingdom and southern Balkan region. On the other hand, models also agree well about the decrease in streamflow droughts in northeastern Europe, Scandinavia, the Baltic countries, and northern parts of Poland. A more mixed pattern with higher variability in low-flow regimes across streamflow drought simulations is evident mainly over the transition zone across central Europe and the Carpathians. A common feature for the minimum flow and deficit indicators is the improved agreement in time between projections of the ensemble members in the aforementioned areas, thus, suggesting a stronger signal-tonoise ratio as time proceeds.

Figure 11 shows the resulting $p$ value from Welch's $t$ test for $20 \mathrm{yr}$ minimum flows and deficit volumes. Significance levels appear to be inversely correlated with the ensembleaverage absolute magnitude of change in minimum flows and deficit volumes (see Fig. 8). As the magnitudes of drying in the south and wetting in the north increase with time, the changes become also more robust, confirming a higher signal-to-noise ratio. By the end of the 21 st century, for nearly all river pixels where the ensemble-average change in low-flow measures exceeds $5 \%$, the changes are 

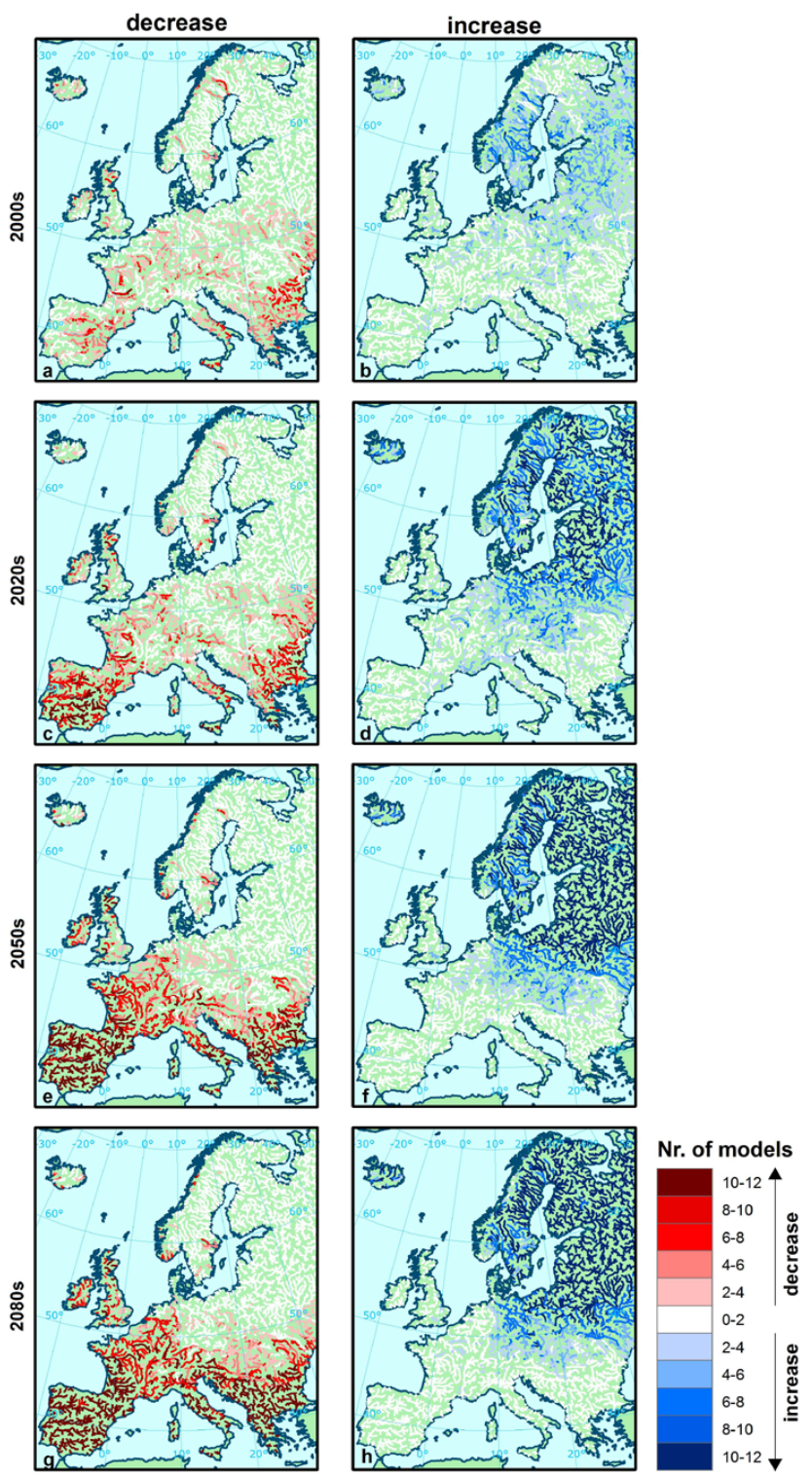

Fig. 10. Consistency of the streamflow drought simulations for different time slices indicated by the number of simulations (out of 12) agreeing in a decrease (left) or increase (right) of more than $5 \%$ in minimum flows.

statistically significant at the $5 \%$ level $(\alpha=0.05)$. In those areas where the ensemble-average changes in low-flow measures are small, higher $p$ values are found, thus suggesting a weaker signal-to-noise ratio. This indicates that the models tend to show less agreement (see also Fig. 10) about the direction (and magnitude) of change in the transition zone between clearly defined regions with increasing (south) and decreasing drought hazard (north). Although not shown here, the same behavior was observed when water consumption is accounted for.

The high consistency amongst the different climate members in projecting streamflow drought changes - already
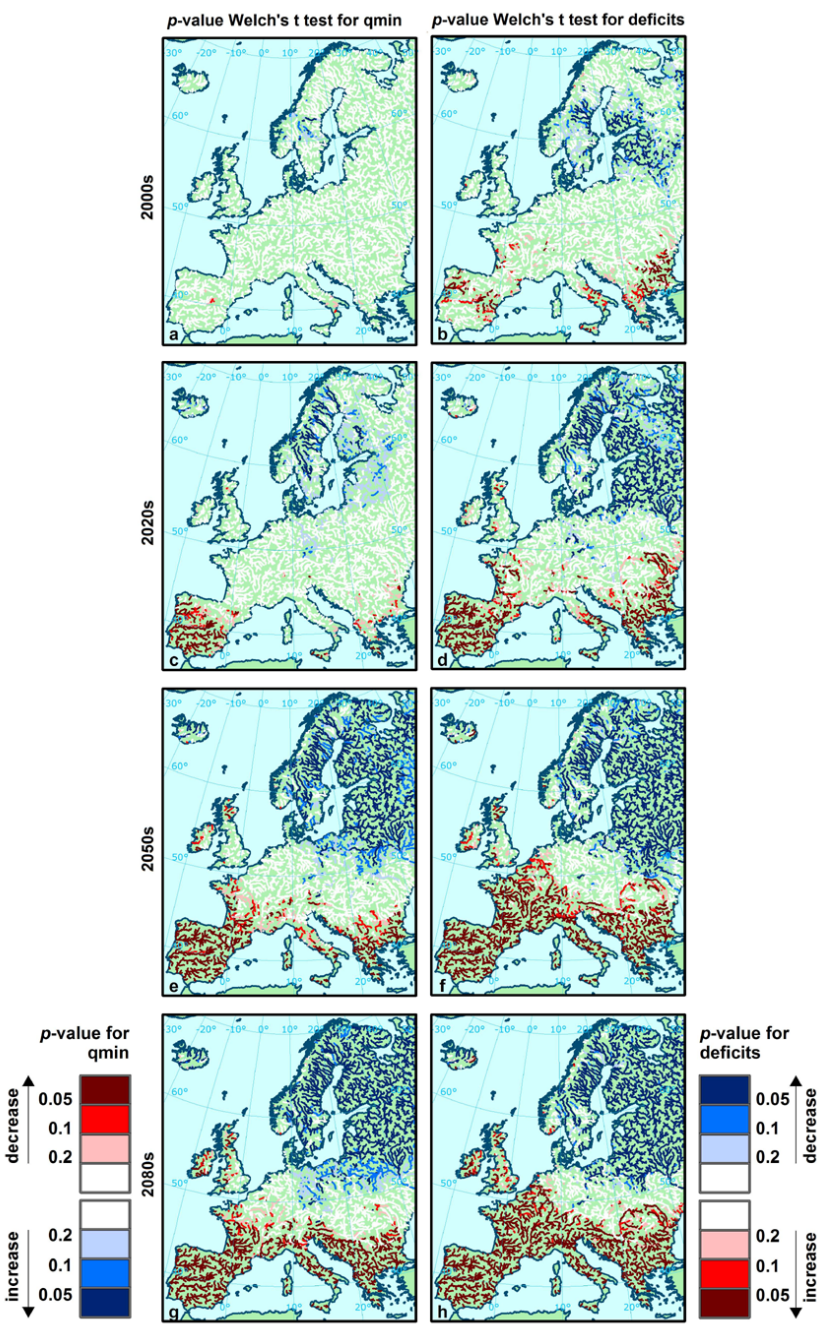

Fig. 11. $p$ value to test significance of the average change in minimum flows (left) and deficit volumes (right) between the corresponding time slices and the control period (1961-1990). $p$ values are obtained on the basis of Welch's $t$ test.

evident in the near-future (Fig. 10c, d) - suggests that the decadal-scale internal climate model variability, which may partially or completely obscure the climate signal in extreme events, is of secondary importance and progressively decreases as time proceeds. Low flows largely depend on imbalances in precipitation over monthly to seasonal timescales, rather than on single events as is the case for example for floods (Rojas et al., 2012). At these scales the changes in rainfall that determine the drought hazard are well established and more consistent between climate models.

Figure 12 shows for the control period and the 2080s (both including water use) the evolution of spread in the ensemble within a year at the selected stations (see Fig. 1). First, over the respective $30 \mathrm{yr}$ time slices daily discharges are calculated for each separate climate-driven run. Then, based on the ensemble of the 12 climate-driven hydrological runs, the 

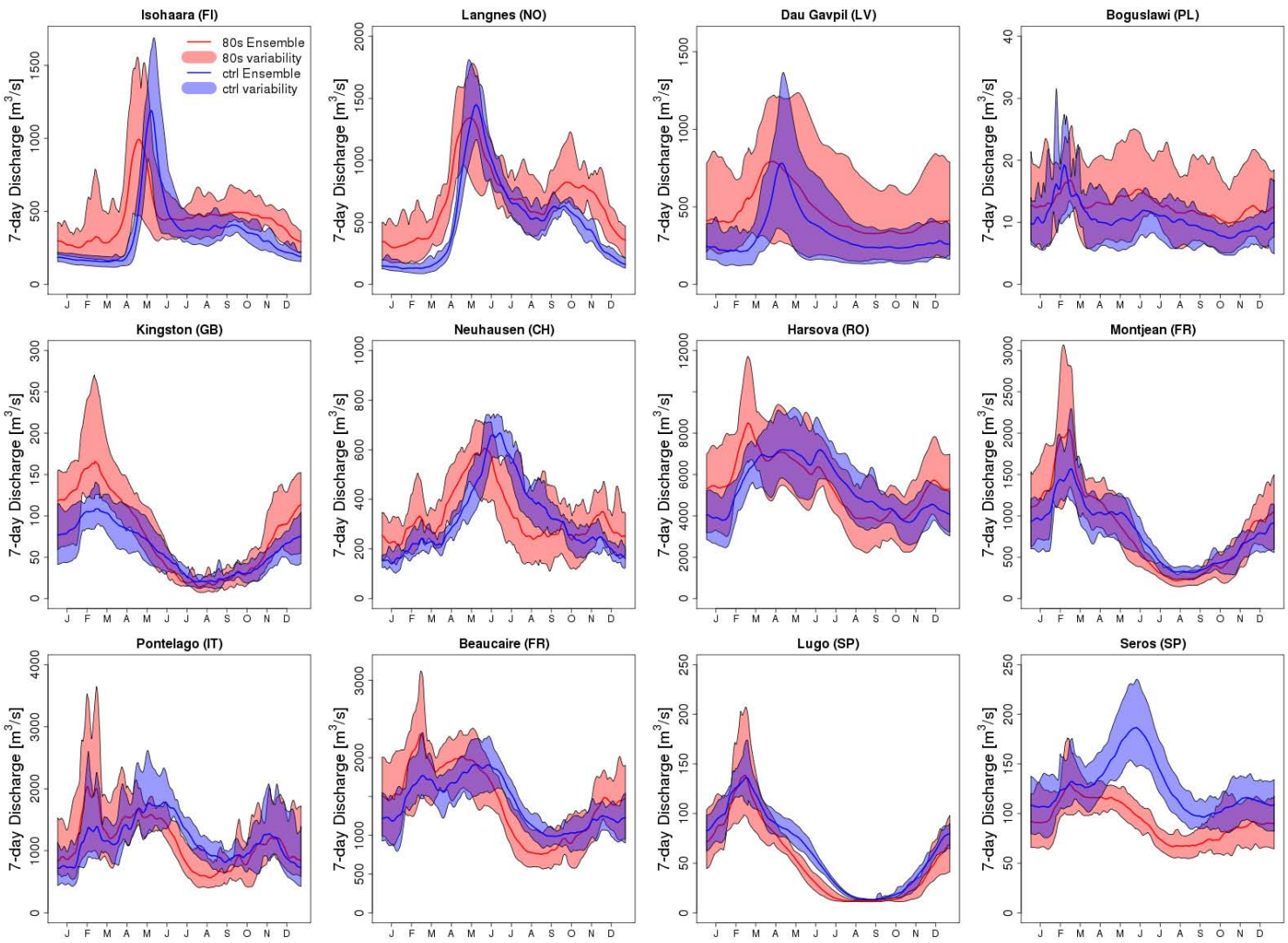

Fig. 12. Inter-annual dynamics in simulated 7 day streamflow for the control period and the 2080s for selected stations (see Fig. 1). The thin blue and red lines represent the ensemble averages for the control and 2080s, respectively. The corresponding shaded areas show the spread amongst ensemble members within the respective period.

daily minimum, maximum and average discharges are calculated. The area shaded in light purple and the blue line show the spread (range between maximum and minimum simulated value) and average for the control period, respectively. The area shaded in orange in combination with the red line represents this information for the 2080s. In general the variability amongst the ensemble members is most pronounced in the high ranges of the flow spectrum, which relates to the inconsistency amongst the models in the representation of extreme precipitation events (Rojas et al., 2012). At all stations, except for Seros, the ensemble spread increases with time compared to the control period, indicating some divergence in the magnitude of the signals projected by the different ensemble members. We also observe a large variability in spread across the stations, with the highest uncertainty both in the control period and the 2080s at stations Dau Gavpil and Boguslawi. This suggests a higher variability in simulated climate in this region, or a higher sensitivity of the hydrological model to climate variability. The latter may be linked to the limited number of stations in this part of Europe used for the calibration of LISFLOOD. Notwithstanding the large uncertainty in the ensemble and the overlap (area shaded in dark purple) in spread for the two periods, the ensem- ble averages still show a clear trend towards increasing low flows (in both seasons) at these stations. At the Harsova and Neuhausen stations, in the nonfrost season the control period spread falls nearly fully within the spread of the 2080 s, suggesting that individual members of the ensemble may show opposite signals of change. This is also expressed by the high $p$ value (hence low significance of change, see Fig. 11) and lower consistency between ensemble members (see Fig. 10) at these locations. The same behavior is observed at Kingston station, although the absolute spread in both periods is much smaller. At stations in southern Europe (see e.g., Montjean, Beaucaire and Lugo and Seros), (nearly) all ensemble member low-flow simulations for the 2080s fall below those of the control period, hence showing a clear increase in severity of low flows in the nonfrost season. At the most northern stations (Langens and Isohaara), the opposite can be observed in the frost season, where all ensemble member low-flow simulations clearly show less severe streamflow drought conditions in the future. In the nonfrost season, more overlap of the spread can be observed, but a clear increase in ensembleaverage low flows is still observed at these stations.

Figure 13 shows the additional uncertainty arising from the fitting compared to that related to climate change. Left 

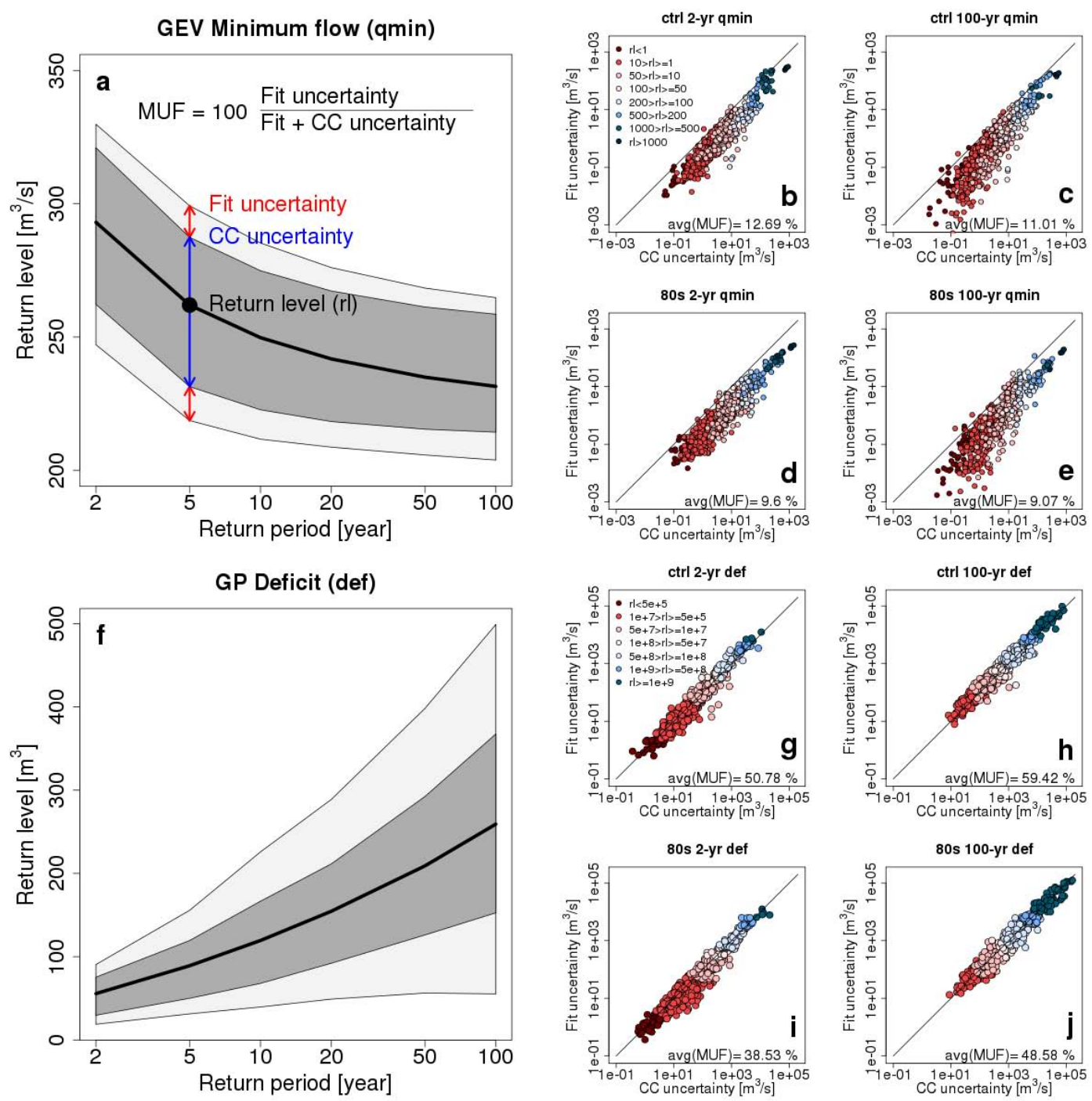

Fig. 13. Relationship between the magnitude of climate change (CC) and EV fitting (Fit) uncertainties over the 446 gauging stations (see Fig. 1) for the control and 2080s periods and for the 2 and $100 \mathrm{yr}$ return periods. Colors of points refer to the magnitude of return levels (rl). GEV results for minimum flows shown in panels (a) through (e), while GP results shown in panels (f) through (j).

panels visually exemplify the uncertainty sources in the EV analysis of annual minimum flows and deficits derived from the hydrological simulations obtained from the different members of the climate ensemble (Fig. 13a and f, respectively). The dark gray area reflects the uncertainty arising from employing alternative climate simulations to force LISFLOOD (CC uncertainty), where the thick black line represents the ensemble average of the fitting distribution (rl). The light gray area, on the other hand, reflects the additional uncertainty arising from the extreme value fitting (Fit uncertainty) and is expressed by the $95 \%$ confidence intervals on the return levels averaged on the twelve hydrological simulations. Marginal uncertainty of fitting (MUF) is calculated as the ratio of uncertainty fitting over the total uncertainty - including climatic and fitting sources - for a given re- turn period. Right panels in Fig. 13 show the relationship between the magnitude of $\mathrm{CC}$ and Fit uncertainty (on the $x$ and $y$ axes, respectively) for all stations (minimum flows and deficit are shown in Fig. 13b-e and Fig. 13g-j, respectively). Point colors refer to the magnitude of return levels (rl), whereas avg(MUF) represents the marginal uncertainty of fitting averaged over all stations.

GEV fitting of annual minimum flows introduces an additional source of uncertainty - minor compared to that of climate change - ranging from 9 to $13 \%$ (Fig. 13b-e). Both Fit and $\mathrm{CC}$ uncertainties tend to decrease with an increasing return period, as an effect of the lower bounded shape of the GEV distribution that tends to converge towards inferior variability in the upper tails. Interestingly, fitting uncertainty tends to decrease faster compared to climate change 
uncertainty along an increasing return period, especially for stations with lower return levels, as exemplified by the corresponding reduction in average MUF. This suggests that the variability of projections of most extreme low-flow events is more influenced by the climate model variability than the fitting confidence. Projections of minimum flows indicate an overall increase in magnitude of uncertainties for both climate and fitting. However, fitting uncertainty is expected to play a secondary role with respect to the climate uncertainty as shown by the reduction in average MUF in the 2080s compared to the control period.

Uncertainty in the GP fitting plays a more important role for the deficit volumes than for the minimum flows, as quantified by higher average MUF ranging from 38 to $60 \%$ (Fig. 13g-j). The GP fitting to the deficit volumes is susceptible to errors as partial duration series of deficits below a threshold often contain, even after smoothing the discharge series as applied here (see Sect. 2.4.), a large number of minor droughts that distort the inference of the scale and especially the shape parameter of the GP distribution. This may result in fitted GP distributions that rapidly overshoot the underlying data used for fitting. Even if the magnitude of both climate and fitting uncertainties increase in future time slices, the average MUF tends to decrease in future projections of deficits, consistently to what is observed for the minimum flows. This confirms that extreme value fitting of annual minima and deficit volumes may introduce additional sources of uncertainty in projections of streamflow droughts playing, however, a secondary role with respect to the climate uncertainty.

\section{Conclusions}

Here we have assessed the implications of global warming and water consumption on low-flow conditions in Europe. We first generated an ensemble of streamflow scenarios from 1961 to 2100 that account for future climate developments and the climate model uncertainty therein - under the IPCC SRES A1B scenario, as well as for changes in consumptive water use under a coherent scenario (Economy First, FP6 SCENES project). In a second step, streamflow drought indices were derived using extreme value analysis and changes between different $30 \mathrm{yr}$ windows were analyzed.

Our analysis has led to the following three main conclusions.

The first conclusion is that due to global warming many river basins in Europe are likely to be more prone to severe water stress. Mostly affected will be southern parts of Europe, where droughts are projected to become considerably more severe over the 21 st century. Minimum flows may be lowered by up to $40 \%$ only due to climate change in the Iberian Peninsula, southernmost regions in France, Italy and the Balkan region. Streamflow deficits, reflecting shortfalls below a threshold flow, show even larger changes in these re- gions, with increases in severity of the events by up to $80 \%$. Also western and central parts of Europe will become more negatively affected and see more severe low-flow conditions. In northern parts of Europe, droughts originating from precipitation anomalies are projected to become considerably less severe.

A second conclusion is that intensive water consumption will aggravate streamflow drought conditions by $10-30 \%$ in southern, western and central Europe, and to a lesser extent also in the United Kingdom. Some regions subject to little or small positive impacts of climate change, may actually see this trend reversed by intensive water use, leading to more severe drought situations. This is the case for large parts of the Benelux, northwestern Germany, northwestern France, and localized parts of the United Kingdom and central and eastern European countries (Slovakia, Czech Republic, Hungary and Romania). We note that in this study only changes in climatology and water consumption are considered. Land use dynamics and consequent changes in vegetation characteristics (e.g., leaf area index) may affect evapotranspiration as well as soil moisture redistribution and groundwater recharge, and consequently the development of droughts.

A third conclusion is that the model projections are fairly consistent amongst the different climate ensemble members. This results in projected strong signals for southern (negative signal, or more severe droughts) and northern (positive change) Europe that show high statistical significance. We note that we used 12 ensemble members originating from 4 GCMs and 7 RCMs. This may not fully sample climate model uncertainty, but it currently constitutes the largest consistent ensemble of climate simulations for Europe. Extreme value fitting of annual minima and deficit volumes may introduce additional sources of uncertainty in projections of streamflow droughts, however, it seems secondary with respect to the climate uncertainty.

The expected changes in streamflow drought presented herein largely agree with those based on the analysis of projections of climate and land surface scheme variables (e.g., Heinrich and Gobiet, 2012; Sienz et al., 2012). The strong signals in increasing drought severity that show high statistical significance indicate that many sub-regions in Europe will increasingly face water stress throughout the 21 st century. Southern regions of Europe, which already suffer most from limited water availability, will be affected hardest, but also other regions in western, central and eastern Europe will likely face more stringent drought conditions. The strong reductions in water availability in low-flow periods that will happen more frequently will increase the competition for water amongst sectors (e.g., energy, agriculture, households). This may pose unforeseen challenges for policy makers and water managers in the regions affected to map out adequate adaptation strategies in order to minimize the socioeconomic and environmental impacts of these changes.

We point out that our analysis focuses on the A1B pathway of climate change and a consistent water use 
consumption scenario, and that possible uncertainty in streamflow droughts arising from the hydrological modeling is neglected. Future developments should focus on an ensemble-based approach that considers multiple combinations of emission/water use scenarios, GCMs-RCMs and hydrological models to depict a picture that is comprehensive of all possible realizations of future low-flow conditions and that accounts for all the involved sources of uncertainty.

It should be noted that emission and water use scenarios are not forecasts or predictions, instead they reflect plausible future emissions and water requirements based on diverse driving forces, such as patterns of economic and population growth and technology development. The A1B scenario used here represents a medium emissions scenario, which leads to an increase in average global temperature of up to $3.4^{\circ} \mathrm{C}$ by 2100 , relative to the period 1961-1990. The use of alternative emission scenarios could show significant differences in future streamflow drought conditions in Europe. For example, and for illustrative purposes only, a warmer climate resulting from rising radiative forcing and emissions (e.g., RCP8.5, Moss et al., 2010), in combination with persisting anticyclonic pressure systems, could lead to lower precipitation patterns, high winds and low relative humidity, thus, likely inducing longer dryness periods and increased evapotranspiration. Such meteorological effects may translate into soil moisture deficiency, and then into streamflow droughts even more pronounced than those observed in our study. It seems reasonable to assume an opposite tendency in case of a less prominent warming (e.g., RCP2.6, Moss et al., 2010). Regarding water use scenarios, the EcF scenario used in our analysis represents a future with the largest amount of water abstractions with respect to the alternative pathways (FoE, PoR, SuE scenarios developed in the SCENES project) (Flörke et al., 2011). Hence, we can realistically argue that our results show the worst case of projected streamflow droughts in relation to the currently available scenarios of water requirements in Europe.

Acknowledgements. We acknowledge past and present colleagues at the JRC who assisted over the years in developing and calibrating LISFLOOD. Data used in this work was funded by the EU-FP6 projects ENSEMBLES (contract no. 505539) and SCENES (contract no. 036822), whose support is gratefully acknowledged. We thank A. Dosio for the bias correction of the ENSEMBLES climate simulations and M. Zambrano-Bigiarini for assistance in $\mathrm{R}$ coding. We acknowledge the careful reviews by Anne van Loon and the anonymous reviewer which helped to improve the manuscript. We are also grateful to the Editor for the efficient handling of the review process and the constructive comments.

Edited by: B. van den Hurk

\section{References}

Alcamo, J.: Environmental Futures, 2. The Practice of Environmental Scenario Analysis, Elsevier B.V., New York, USA, 2008.

Alcamo, J., Döll, P., Henrichs, T., Kaspar, F., Lehner, B., Rösch, T., and Siebert, S.: Development and testing of the WaterGAP 2 global model of water use and availability, Hydrol. Sci. J., 48, 317-337, 2003.

Aus der Beek, T., Flörke, M., Lapola, D. M., and Schaldach R.: Modelling historical and current irrigation water demand on the continental scale: Europe, Adv. Geosci., 27, 79-85, 2010, http://www.adv-geosci.net/27/79/2010/.

Beirlant, J., Goegebeur, Y., Segers, J., Teugels, J., De Waal, D., and Ferro, C.: Statistics of extremes - Theory and applications, Wiley series in probability and statistics, Wiley, Chichester, 1 Edn., 2004.

Beniston, M., Stephenson, D., Christensen, O., Ferro, C., Frei, C., Goyette, S., Halsnaes, K., Holt, T., Jylhä, K., Koffi, B., Palutikof, J., Schöll, R., Semmler, T., and Woth, K.: Current and future extreme climatic events in Europe: observation and modeling studies conducted within the EU PRUDENCE project, Clim. Chang., 81, 71-95, 2007.

Blenkinsop, S. and Fowler, H. J.,: Changes in European drought characteristics projected by the PRUDENCE regional climate models, Int. J. Climatol., 27, 1595-1610, 2007.

Brooks, R. T.: Potential impacts of global climate change on the hydrology and ecology of ephemeral freshwater systems of the forests of the northeastern United States, Clim. Chang., 95, 469483, 2009.

Burke, E. J. and Brown, S. J.: Evaluating uncertainties in the projection of future drought, J. Hydrometeorol., 9, 292-299, 2008.

Calanca, P.: Climate change and drought occurrence in the Alpine region: How severe are becoming the extremes?, Global Planet. Change, 57, 151-160, 2007.

Christensen, J. and Christensen, O.: A summary of the PRUDENCE model projections of changes in European climate by the end of this century, Clim. Chang., 81, 7-30, doi:10.1007/s10584-0069210-7, 2007

Christensen, J. H., Hewitson, B., Busuioc, A., Chen, A., Gao, X., Held, I., Jones, R., Kolli, R. K., Kwon, W.-T., Laprise, R., Magaña Rueda, V., Mearns, L., Menéndez, C. G., Räisänen, J., Rinke, A., Sarr A., and Whetton, P.: Regional Climate Projections, in: Climate Change 2007: The Physical Science Basis, Contribution of Working Group I to the Fourth Assessment Report of the Intergovernmental Panel on Climate Change, edited by: Solomon, S., Qin, D., Manning, M., Chen, Z., Marquis, M., Averyt, K. B., Tignor, M., and Miller, Cambridge University Press, Cambridge, United Kingdom and New York, NY, USA, 2007.

Christensen, J., Boberg, F., Christensen, O., and Lucas-Picher, P.: On the need for bias correction of regional climate change projections of temperature and precipitation, Geophys. Res. Lett., 35, L20709, doi:10.1029/2008GL035694, 2008.

Christensen, J. H., Kjellström, E., Giorgi, F., Lenderink, G., and Rummukainen, M.: Weight assignment in regional climate models, Clim. Res., 44, 179-194, 2010.

Coles, S.: An introduction to statistical modeling of extreme values, Springer series in statistics, Springer, London, 1 Edn., 2001.

Collins, M., Booth, B., Harris, G., Murphy, J., Sexton, D., and Webb, M.: Towards quantifying uncertainty in transient climate 
change, Clim. Dynam., 27, 127-147, doi:10.1007/s00382-0060121-0, 2006.

Coppola, E., Giorgi, F., Rauscher, S. A., and Piani, C.: Model weighting based on mesoscale structures in precipitation and temperature in an ensemble of regional climate models, Clim. Res., 44, 121-134, 2010.

Dai, A.: Drought under global warming: A review, Wiley Interdisciplinary Reviews: Climate Change, 2, 45-65, 2011.

Dai, A.: Increasing drought under global warming in observations and models, Nat. Clim. Change, 3, 52-58, doi:10.1038/nclimate1633, 2013.

Déqué, M., Rowell, D. P., Lüthim, D., Giorgi, F., Christensen, J. H., Rockel, B., Jacob, D., Kjellström, E., de Castro, M., and van den Hurk, B. J. J. M.: An intercomparison of regional climate simulations for Europe: Assessing uncertainties in model projections, Clim. Change, 81, 53-70, doi:10.1007/s10584-006-9228$\mathrm{x}, 2007$.

Déqué, M., Somot, S., Sanchez-Gomez, E., Goodess, C. M., Jacob, D., Lenderink, G., and Christensen, O.B .: The spread amongst ENSEMBLES regional scenarios: Regional climate models, driving general circulation models and interannual variability, Clim. Dynam., 38, 951-964, 2012.

Déqué, M. and Somot, S.: Weighted frequency distributions express modelling uncertainties in the ENSEMBLES regional climate experiments, Clim. Res. , 44, 195-209, 2010.

de Wit, M. J. M., van den Hurk, B., Warmerdam, P. M. M., Torfs, P. J. J. F., Roulin, E., and van Deursen, W. P. A.: Impact of climate change on low-flows in the river Meuse, Clim. Change, 82, 351372, 2007.

Diaz-Nieto, J. and Wilby, R. L.: A comparison of statistical downscaling and climate change factor methods: impacts on low flows in the River Thames, United Kingdom, Clim. Change, 69, 245268, 2005.

Döll, P., Kaspar, F., and Lehner, B.: A global hydrological model for deriving water availability indicators: model tuning and validation, J. Hydrol., 270, 105-134, 2003.

Döll, P., Fiedler, K., and Zhang, J.: Global-scale analysis of river flow alterations due to water withdrawals and reservoirs, Hydrol. Earth Syst. Sci., 13, 2413-2432, doi:10.5194/hess-13-24132009, 2009.

Dosio, A. and Paruolo, P.: Bias correction of the ENSEMBLES high-resolution climate change projections for use by impact models: Evaluation on the present climate, J. Geophys. Res., 116, D16106, doi:10.1029/2008JD011438, 2011.

Dosio, A., Paruolo, P., and Rojas, R.: Bias correction of the ENSEMBLES high resolution climate change projections for use by impact models: Analysis of the climate change signal, J. Geophys. Res., 117, D17110, doi:10.1029/2011JD015934, 2012.

EC: Addressing the challenge of water scarcity and droughts in the European Union. Communication from the Commission to the European Parliament and the Council, COM/2007/0414 final, 2007.

EC: Report on the Review of the European Water Scarcity and Droughts Policy. Communication from the Commission to the European Parliament, the Council, the European Economic and Social Committee and the Committee of the Regions, COM/2012/0672 final, 2012.

EEA: Mapping the impacts of natural hazards and technological accidents in Europe - An overview of the last decade. EEA Tech- nical Report, 144 pp., 13/2010, European Environment Agency, Copenhagen, Denmark, doi:10.2800/62638, ISSN 1725-2237, 2010.

Engeland, K., Hisdal, H., and Frigessi, A.: Practical extreme value modelling of hydrological floods and droughts: a case study, Extremes, 7, 5-30, 2004.

European Environment Agency: Corine land cover 2000, Tech. Rep. 89, Eur. Comm., Brussels, 2002.

Feyen, L. and Dankers, R.: Impact of global warming on streamflow drought in Europe, J. Geophys. Res.-Atmos., 114, D17116, doi:10.1029/2012JD017968, 2009.

Feyen, L., Vrugt, J. A., Nualláin, B. O., van der Knijff, J., and De Roo, A.: Parameter optimisation and uncertainty assessment for large-scale streamflow simulation with the LISFLOOD model, J. Hydrol., 332, 276-289, 2007.

Feyen, L., Kalas, M., and Vrugt, J. A.: Semi-distributed parameter optimization and uncertainty assessment for large-scale streamflow simulation using global optimization, Hydrol. Sci. J. , 53, 293-308, 2008.

Fiala, T., Ouarda, T. B. M. J., and Hladný, J.: Evolution of low flows in the Czech Republic, J. Hydrol., 393, 206-218, 2010.

Fleig, A. K., Tallaksen, L. M., Hisdal, H., and Demuth, S.: A global evaluation of streamflow drought characteristics, Hydrol. Earth Syst. Sci., 10, 535-552, doi:10.5194/hess-10-535-2006, 2006.

Flörke, M., Wimmer, F., Laaser, C., Vidaurre, R., Tröltzsch, J., Dworak, T., Stein, U., Marinova, N., Jaspers, F., Ludwig, F., Swart, R., Giupponi, C., Bosello, F., and Mysiak, J.: Climate Adaptation - modelling water scenarios and sectoral impacts, CESR, University of Kassel, Contract No. DG ENV.D.2/SER/2009/003, 2011.

Flörke, M., Bärlund, I., and Kynast, E.: Will climate change affect the electricity production sector? A European study, J. Water Clim. Change, 3, 44-54, 2012.

Flörke, M., Kynast, E., Bärlund, I., Eisner, S., Wimmer, F., and Alcamo, J.: Domestic and industrial water uses of the past 60 years as a mirror of socio-economic development: A global simulation study, Global Environ. Chang., 23, 144-156, 2013.

Fowler, H. J., Ekström, M., Blenkinsop, S., and Smith, A. P.: Estimating change in extreme European precipitation using a multimodel ensemble, J. Geophys. Res., 112, D18104, doi:10.1029/2007JD008619, 2007.

Gilleland, E. and Katz, R. W.: Analyzing seasonal to interannual extreme weather and climate variability with the extremes toolkit (extRemes), paper presented at 18th Conference on Climate Variability and Change, Am. Meteorol. Soc., Atlanta, Ga., 2005.

Goodison, B. E., Louie, P. Y. T., and Yang, D.: WMO solid precipitation measurement intercomparison, WMO/TD 872, 212 pp., World Meteorol. Org., Geneva, 1998.

Gudmundsson, L., Tallaksen, L.M., Stahl, K., Clark, D.B., Dumont, E., Hagemann, S., Bertrand, N., Gerten, D., Heinke, J., Hanasaki, N., Voss, F., and Koirala, S.: Comparing large-scale hydrological model simulations to observed runoff percentiles in Europe, J. Hydrometeorol., 13, 604-620, 2012.

Hagemann, S., Chen, C., Clark, D. B., Folwell, S., Gosling, S. N., Haddeland, I., Hanasaki, N., Heinke, J., Ludwig, F., Voss, F., and Wiltshire, A. J.: Climate change impact on available water resources obtained using multiple global climate and hydrology models, Earth Syst. Dynam., 4, 129-144, doi:10.5194/esd4-129-2013, 2013. 
Haylock, M., Hofstra, N., Klein, A., Klok, E., Jones, P., and New, M.: A European daily high-resolution gridded data set of surface temperature and precipitation for 1950-2006, J. Geophys. Res., 113, D20119, doi:10.1029/2008JD010201, 2008.

Heinrich, G. and Gobiet, A.: The future of dry and wet spells in Europe: A comprehensive study based on the ENSEMBLES regional climate models, Int. J. Climatol., 32, 1951-1970, 2012.

Hiederer, R. and de Roo, A.: A European flow network and catchment data set, technical report, Joint Res. Cent., Eur. Comm., Brussels, 2003.

Hirabayashi, Y., Kanae, S., Emori, S., Oki, T., and Kimoto, M.: Global projections of changing risks of floods and droughts in a changing climate, Hydrol. Sci. J., 53, 754-772, 2008.

Hisdal, H., Stahl, K., Tallaksen, L. M., and Demuth, S.: Have droughts in Europe become more severe or frequent?, Int. J. Climatol., 21, 317-333, 2001.

Hoerling, M., Eischeid, J., Perlwitz, J., Quan, X., Zhang, T., and Pegion, P.: On the increased frequency of Mediterranean drought, J. Climate, 25, 2146-2161, 2012.

Hurkmans, R., Terink, W., Uijlenhoet, R., Torfs, P., Jacob, D., and Troch, P. A.: Changes in streamflow dynamics in the Rhine Basin under three high-resolution regional climate scenarios, J. Climate, 23, 679-699, 2010.

IPCC: IPCC Fourth Assessment Report, Working Group II Report "Impacts, Adaptation and Vulnerability", 2007.

IPCC: Managing the Risks of Extreme Events and Disasters to Advance Climate Change Adaptation, A Special Report of Working Groups I and II of the Intergovernmental Panel on Climate Change, edited by: Field, C. B., Barros, V., Stocker, T. F., Qin, D., Dokken, D. J., Ebi, K. L., Mastrandrea, M. D., Mach, K. J., Plattner, G.-K., Allen, S. K., Tignor, M., and Midgley, P. M., Cambridge University Press, Cambridge, UK, and New York, NY, USA, 582 pp., 2012.

Kämäri, J., Alcamo, J., Bärlund, I., Duel, H., Farquharson, F., Flörke, M., Fry, M., Houghton-Carr, H., Kabat, P., Kaljonen, M., Kok, K., Meijer, K. S., Rekolainen, S., Sendzimir, J., Varjopuro, R., and Villars, N.: Envisioning the future of water in Europe - the SCENES project, European Water Association, E-Water, 2008.

Katz, R. W., Parlange, M. B., and Naveau, P.: Statistics of extremes in hydrology, Adv. Water Resour., 25, 1287-1304, 2002.

Kendon, E., Jones, R., Kjellström, E., and Murphy, J.: Using and designing GCM-RCM ensemble regional climate projections, J. Climate, 23, 6485-6503, doi:10.1175/2010JCLI3502.1, 2010.

King, D., Daroussin, J., and Tavernier, R.: Development of a soil geographic database from the Soil Map of the European Communities, Catena, 21, 37-56, doi:10.1016/0341-8162(94)900302, 1994.

Kok, K., van Vliet, M., Bärlund, I., Dubel, A., and Sendzimir, J.: Combining participative backcasting and explorative scenario development: Experiences from the SCENES project, Technol. Forecast. Social Change, 78, 835-851, 2011.

Korhonen, J. and Kuusisto, E.: Long-term changes in the discharge regime in Finland, Hydrol. Res., 41, 253-268, 2010.

Lehner, B., Döll, P., Alcamo, J., Henrichs, T., and Kaspar, F.: Estimating the impact of global change on flood and drought risks in Europe: a continental integrated analysis, Clim. Change, 75, 273-299, 2006
Lenderink, G.: Exploring metrics of extreme daily precipitation in a large ensemble of regional climate model simulations, Clim. Res., 44, 151-166, 2010.

Majone, B., Bovolo, C. I., Bellin, A., Blenkinsop, S., and Fowler, H. J.: Modeling the impacts of future climate change on water resources for the Gállego river basin (Spain), Water Resour. Res., 48, W01512, doi:10.1029/2011WR010985, 2012.

Mishra, A. K. and Singh, V. P.: A review of drought concepts, J. Hydrol., 391, 202-216, 2010.

Moss, R. H., Edmonds, J. A., Hibbard, K. A., Manning, M. R., Rose, S. K., van Vuuren, D. P., Carter, T. R., Emori, S., Kainuma, M., Kram, T., Meehl, G. A., Mitchell, J. F. B., Nakicenovic, N., Riahi, K., Smith, S. J., Stouffer, R. J., Thomson, A. M., Weyant, J. P., and Wilbanks, T. J.: The next generation of scenarios for climate research and assessment, Nature 463, 747-756, doi:10.1038/nature08823, 2010.

Murphy, J. M., Sexton, D. M. H., Barnett, D. H., Jones, G. S., Webb, M. J., Collins, M., and Stainforth, D. A.: Quantification of modelling uncertainties in a large ensemble of climate change simulations, Nature, 430, 768-772, 2004.

Murphy, J. M., Booth, B. B. B., Collins, M., Harris, G. R., Sexton, D. M. H., and Webb, M. J.: A methodology for probabilistic predictions of regional climate change from perturbed physics ensembles, Philos. Trans. R. Soc. A: Mathematical, Physical and Engineering Sciences, 365, 1993-2028, 2007.

Najafi, M., Moradkhani, H., and Jung, I.: Assessing the uncertainties of hydrologic model selection in climate change impact studies, Hydrol. Processes, 25, 2814-2826, doi:10.1002/hyp.8043, 2011.

Nakicenovic, N. and Swart, R. (Eds.): IPCC Special Report on Emission Scenarios, Cambridge Univ. Press, Cambridge, UK, 2000.

Nikulin, G., Kjellström, E., Hansson, U., Strandberg, G., and Ullerstig, A.: Evaluation and future projections of temperature, precipitation and wind extremes over Europe in an ensemble of regional climate simulations, Tellus, Series A: Dynamic Meteorology and Oceanography, 63, 41-55, 2011.

Orlowsky, B. and Seneviratne, S. I.: Elusive drought: uncertainty in observed trends and short- and long-term CMIP5 projections, Hydrol. Earth Syst. Sci., 17, 1765-1781, doi:10.5194/hess-171765-2013, 2013.

Piani, C., Haerter, J., and Coppola, E.: Statistical bias correction for daily precipitation in regional climate models over Europe, Theor. Appl. Climatol., 99, 187-192, doi:10.1007/s00704-0090134-9, 2010a.

Piani, C., Weedon, G., Best, M., Gomes, S., Viterbo, P., Hagemann, S., and Haerter, J.: Statistical bias correction of global simulated daily precipitation and temperature for the application of hydrological models, J. Hydrol., 395, 199-215, doi:10.1016/j.jhydrol.2010.10.024, 2010b.

Räisänen, J. and Eklund, J.: 21st Century changes in snow climate in Northern Europe: A high-resolution view from ENSEMBLES regional climate models, Clim. Dynam., 38, 2575-2591, 2012.

Renard, B., Lang, M., Bois, P., Dupeyrat, A., Mestre, O., Niel, H., Sauquet, E., Prudhomme, C., Parey, S., Paquet, E., Neppel, L., and Gailhard, J.: Regional methods for trend detection: Assessing field significance and regional consistency, Water Resour. Res., 44, W08419, doi:10.1029/2007WR006268, 2008. 
Rijks, D., Terres, J., and Vossen, P.: Agrometeorological applications for regional crop monitoring and production assessment, Tech. Rep. EUR 17735, Joint Res. Cent., Ispra, Italy, 1998.

Rojas, R., Feyen, L., Dosio, A., and Bavera, D.: Improving panEuropean hydrological simulation of extreme events through statistical bias correction of RCM-driven climate simulations, Hydrol. Earth Syst. Sci., 15, 2599-2620, doi:10.5194/hess-15-25992011, 2011.

Rojas, R., Feyen, L., Bianchi, A., and Dosio, A.: Assessment of future flood hazard in Europe using a large ensemble of biascorrected regional climate simulations, J. Geophys. Res.-Atmos., 117, D17109, doi:10.1029/2012JD017461, 2012.

Rowell, D. P.: A scenario of European climate change for the late 21st century: seasonal means and interannual variability, Clim. Dynam., 25, 837-849, doi:10.1007/s00382-005-0068-6, 2005.

Schaldach, R., Koch, J., Aus der Beek, T., Kynast, E., and Flörke, M.: Current and future irrigation water requirements in panEurope: a comparative analysis of influencing factors, Global Planet. Change, 94-95, 33-45, 2012.

Schär, C., Vidale, P. L., Lüthi, D., Frei, C., Häberli, C., Liniger, M. A., and Appenzeller, C.: The role of increasing temperature variability in European summer heatwaves, Nature, 427, 332336, 2004

Schmidt, G. and Benítez-Sanz, C.: How to distinguish water scarcity and drought in EU water policy?, GWF Discussion Paper 1333, Global Water Forum, Canberra, Australia, 2013.

Sheffield, J. and Wood, E. F.: Projected changes in drought occurrence under future global warming from multi-model, multiscenario, IPCC AR4 simulations, Clim. Dynam., 31, 79-105, 2008.

Sheffield, J., Wood, E. F., and Roderick, M. L.: Little change in global drought over the past 60 years, Nature, 491, 435-438, doi:10.1038/nature11575, 2012.

Sienz, F., Bothe, O., and Fraedrich, K.: Monitoring and quantifying future climate projections of dryness and wetness extremes: SPI bias, Hydrol. Earth Syst. Sci., 16, 2143-2157, doi:10.5194/hess16-2143-2012, 2012.

Smakhtin, V. U.: Low flow hydrology: a review, J. Hydrol., 240, 147-186, 2001.

Stahl, K., Hisdal, H., Hannaford, J., Tallaksen, L. M., van Lanen, H. A. J., Sauquet, E., Demuth, S., Fendekova, M., and Jódar, J.: Streamflow trends in Europe: evidence from a dataset of nearnatural catchments, Hydrol. Earth Syst. Sci., 14, 2367-2382, doi:10.5194/hess-14-2367-2010, 2010.

Stahl, K., Tallaksen, L. M., Gudmundsson, L., and Christensen, J. H.: Streamflow data from small basins: a challenging test to high resolution regional climate modeling, J. Hydrometeorol., 12, 900-912, 2011.

Stahl, K., Tallaksen, L. M., Hannaford, J., and van Lanen, H. A. J.: Filling the white space on maps of European runoff trends: estimates from a multi-model ensemble, Hydrol. Earth Syst. Sci., 16, 2035-2047, doi:10.5194/hess-16-2035-2012, 2012.

Svensson, C., Kundzewicz, Z. W., and Maurer, T.: Trend detection in river flow series: 2. Flood and low-flow index series, Hydrol. Sci. J., 50, 811-824, 2005.

Tallaksen, L. M., Madsen, H., and Clausen, B.: On the definition and modeling of streamflow drought duration and deficit volume, Hydrol. Sci. J., 42, 15-33, 1997.
Tallaksen, L. M. and van Lanen, H. A. J. (Eds.): Hydrological Drought: Processes and Estimation Methods for Streamflow and Groundwater, Dev. Water Sci., Vol. 48, Elsevier, Amsterdam, 2004.

Teutschbein, C. and Seibert, J.: Regional climate models for hydrological impact studies at the catchment scale: A review of recent model strategies, Geogr. Compass, 4, 834-860, doi:10.1111/j.1749-8198.2010.00357.x, 2010.

Themeß1, M., Gobiet, A., and Leuprecht, A.: Empirical-statistical downscaling and error correction of daily precipitation from regional climate models, International J. Climatol., 31, 1530-1544, doi:10.1002/joc.2168, 2011.

van der Knijff, J.: LISVAP: Evaporation Pre-Processor for the LISFLOOD Water Balance and Flood Simulation Model, EUR $22639 \mathrm{EN} / 2 ., 2008$.

van der Knijff, J., Younis, J., and de Roo, A.: LISFLOOD: A GIS-based distributed model for river basin scale water balance and flood simulation, Int. J. Geogr. Inf. Sci., 24, 189-212, doi:10.1080/13658810802549154, 2010.

van der Linden, P. and Mitchell, J.: ENSEMBLES: Climate change and its impacts: Summary of research and results from the ENSEMBLES project. Technical Report, Met Office Hadley Centre, 2009.

Van Loon, A. F. and Van Lanen, H. A. J.: Making the distinction between water scarcity and drought using an observation-modeling framework, Water Resour. Res., 49, 1483-1502, 2013.

Van Loon, A. F., Van Huijgevoort, M. H. J., and Van Lanen, H. A. J.: Evaluation of drought propagation in an ensemble mean of large-scale hydrological models, Hydrol. Earth Syst. Sci., 16, 4057-4078, doi:10.5194/hess-16-4057-2012, 2012.

Vidal, J.-P. and Wade, S.: A multimodel assessment of future climatological droughts in the United Kingdom, Int. J. Climatol., 29, 2056-2071, 2009.

Vidal, J.-P., Martin, E., Kitova, N., Najac, J., and Soubeyroux, J.M.: Evolution of spatio-temporal drought characteristics: validation, projections and effect of adaptation scenarios, Hydrol. Earth Syst. Sci., 16, 2935-2955, doi:10.5194/hess-16-29352012, 2012.

Von Storch, H. and Zwiers, F.W.: Statistical Analysis in Clim. Res., Cambridge Univ. Press, Cambridge, UK, 1999.

Vörösmarty, C. J., Green, P., Salisbury, J., and Lammers, R. B.: Global water resources: vulnerability from climate change and population growth, Science, 289, 284-288, 2000.

Wada, Y., van Beek, L. P. H., Wanders, N., and Bierkens, M. F. P.: Human water consumption intensifies hydrological drought worldwide, Environ. Res. Lett., 8, 1-14, doi:10.1088/17489326/8/3/034036, 2013a.

Wada, Y., Wisser, D., Eisner, S., Flörke, M., Gerten, D., Haddeland, I., Hanasaki, N., Masaki, Y., Portmann, F., Stacke, T., Tessler, Z., and Schewe, J.: Multi-model projections and uncertainties of irrigation water demand under climate change, Geophys. Res. Lett., 40, 4626-4632, doi:10.1002/grl.50686, 2013 b.

Weiss, M., Flörke, M., Menzel, L., and Alcamo, J.: Model-based scenarios of Mediterranean droughts, Adv. Geosci., 12, 145-151, 2007,

http://www.adv-geosci.net/12/145/2007/.

Welch, B. L.: The generalization of "student's" problem when several different population variances are involved, Biometrika, 34, 28-35, 1947. 
Wilby, R.: Uncertainty in water resource model parameters used for climate change impact assessment, Hydrol. Process., 19, 32013219, doi:10.1002/hyp.5819, 2005.

Wilson, D., Hisdal, H., and Lawrence, D.: Has streamflow changed in the Nordic countries? - Recent trends and comparisons to hydrological projections, J. Hydrol., 394, 334-346, 2010.

Woo, M.-K. and Tarhule, A.: Streamflow droughts of northern Nigerian rivers, Hydrol. Sci. J., 39, 19-34, 1994.
Wösten, J., Lilly, A., and Le Bas, C.: Development and use of a database of hydraulic properties of European soils, Geoderma, 90, 169-185, doi:10.1016/s0016-7061(98)00132-3, 1999.

Yang, D. and Ohata, T.: A bias-corrected Siberian regional precipitation climatology, J. Hydrometeorol., 2 122-139, 2001.

Zelenhasic, E. and Salvai, A.: A method of streamflow drought analysis, Water Resour. Res., 23, 156-168, doi:10.1029/WR023i001p00156, 1987. 